\title{
A Novel Approach to Arcing Faults Characterization Using Multivariable Analysis and Support Vector Machine
}

\author{
John Morales ${ }^{1,2, *}$, Eduardo Muñoz ${ }^{1}$, Eduardo Orduña ${ }^{2}$ and Gina Idarraga-Ospina ${ }^{3}$ \\ 1 Carrera de Ingeniería Mecatrónica, Universidad Politécnica Salesiana, Cuenca 010105, Ecuador; \\ jmoralesg@ups.edu.ec \\ 2 Instituto de Energía Eléctrica, Universidad Nacional de San Juan, San Juan J5400ARL, Argentina; \\ jmorales@iee.unsj.edu.ar \\ 3 Facultad de Ingeniería Mecánica y Eléctrica, Universidad Autónoma de Nuevo León, Monterrey León C.P. \\ 64460, Mexico; gina.idarragao@uanl.mx \\ * Correspondence: jmoralesg@ups.edu.ec; Tel.: +593-7-286-2213
}

Received: 30 April 2019; Accepted: 27 May 2019; Published: 3 June 2019

\begin{abstract}
Based on the Institute of Electrical and Electronics Engineers (IEEE) Standard C37.104-2012 Power Systems Relaying Committee report, topics related to auto-reclosing in transmission lines have been considered as an imperative benefit for electric power systems. An important issue in reclosing, when performed correctly, is identifying the fault type, i.e., permanent or temporary, which keeps the faulted transmission line in service as long as possible. In this paper, a multivariable analysis was used to classify signals as permanent and temporary faults. Thus, by using a simple convolution process among the mother functions called eigenvectors and the fault signals from a single end, a dimensionality reduction was determined. In this manner, the feature classifier based on the support vector machine was used for acceptably classifying fault types. The algorithm was tested in different fault scenarios that considered several distances along the transmission line and representation of first and second arcs simulated in the alternative transients program ATP software. Therefore, the main contribution of the analysis performed in this paper is to propose a novel algorithm to discriminate permanent and temporary faults based on the behavior of the faulted phase voltage after single-phase opening of the circuit breakers. Several simulations let the authors conclude that the proposed algorithm is effective and reliable.
\end{abstract}

Keywords: arcing fault identification; autoreclosure; relay; transient analysis

\section{Introduction}

It is clear that electric power systems (EPS) have been considered as one of the most important developments of humanity, and its principal objective is to supply electric power maintaining a very high level of continuity of service. Nevertheless, each of the steps of generation, transmission and distribution has its own difficulties, where abnormal conditions called short circuits can be especially present on transmission lines (TLs). Thus, TLs become extremely critical [1]. Based on statistics, $80 \%$ of faults in overhead TLs are single-phase and of temporary type. When a temporary fault on TLs is presented, which is mostly accompanied by an electric arc, the main goal of protection relays is to isolate the faulted line temporarily until the fault arc path de-ionizes and re-energize it, which is called reclosing [2,3]. Hence, in many cases, the fault on TLs is not solid and is caused by different conditions such as flying birds, branches of trees and others, where the electrical arc plays a major role and permanent and temporary fault have different behavior; see Section 4.2. 
During arcing faults, the appearance of a long arc in free air must be modeled, i.e., the nonlinear nature of the arc should be considered and clearly represented. As it is mentioned in References $[4,5]$, the unconstrained long fault arc in the air could be studied and modeled by applying the theory of switching arc, and based on that information, it is possible to develop a more precise model of arcing faults. In fact, the latest research only analyzes this phenomenon in the time domain, based on voltage and current waveforms [6,7].

On the other hand, the fastest manner to extinguish an arc associated with a temporary fault is through a three-phase reclosing scheme, where, after opening the TL, a time known as the dead time (DT) will elapse and the breakers of each phase will be closed at each extreme of the TL. In this situation, there would be no voltage source to feed the arc. However, rotors of generation units can accelerate too much, and cause the loss of synchronism during the DT, which would be catastrophic for the stability of the EPS $[8,9]$.

Considering not only the possible problems of three-phase reclosing, but also if the temporary fault is usually single-phase, an effective method is the single-phase reclosing $[10,11]$. In this case, the two healthy phases are kept energized during the fault period, while the faulted phase becomes de-energized temporarily until the arc is cleared. However, the arc cannot be extinguished, immediately. Hence, in single-phase reclosing it is imperative to avoid reclosing when the arc is not cleared yet. Therefore, the main problem with the traditional reclosing method is that there is no guarantee that the fault type is temporary. In fact, the traditional relay algorithm recloses the faulted phase regardless of the fault type [1].

The criterion of equal areas shows the behavior of three-phase opening and reclosing, where the area A1 is greater than the area A2, Figure 1, which means that the synchronous machine loses synchronism [8].

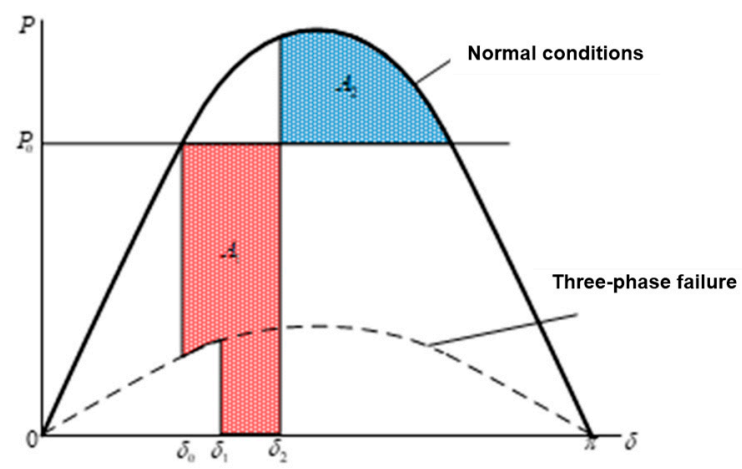

Figure 1. Effect of a three-phase opening and reclosing using the equal area criteria.

Figure 2 shows the single-phase opening and reclosing effect. Thus, area A1 is smaller than area A2. The machine will not lose synchronism [8].

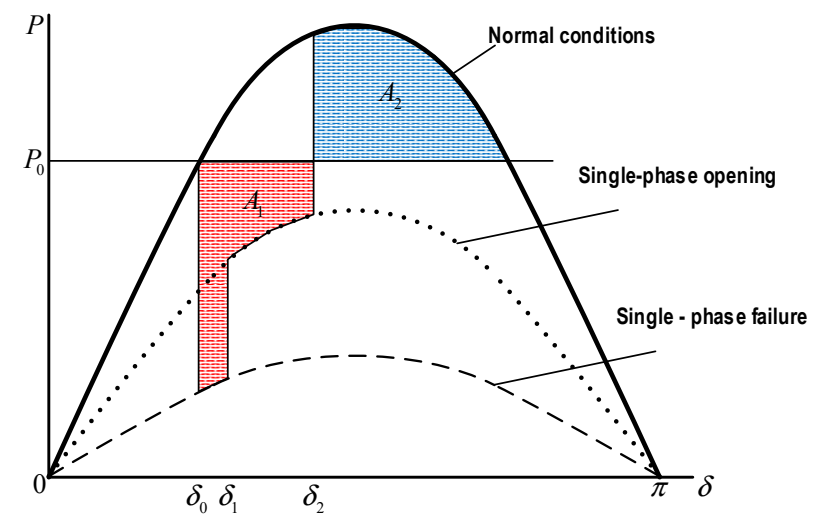

Figure 2. Effect of a single-phase opening and reclosing using the same area criteria. 
When the single-phase fault occurs, the primary arc current occurs and switches at the ends of the failed phase will open, the other phases will remain closed [8].

When the phase-in fault is opened, it is coupled with the healthy phases in an electrostatic way or capacitive coupling (of greater influence) and electromagnetic or inductive coupling. Capacitive coupling generates the secondary arc current that will self-extinguish in few cycles [11].

A successful reclosing will occur when the secondary arc is self-extinguished before the DT. According to Reference [7], for a $500 \mathrm{kV}$ system, this time varies between 0.4 to $0.5 \mathrm{~s}$ and can be obtained from Equation (1), which is a function of the TL voltage level VL [5].

$$
\mathrm{t}=10.5 \frac{V_{L}}{34.5}
$$

During this time, reclosing will occur with or without the clear fault, so the extinction of the secondary arc must be ensured in this period. According to Reference [5], the secondary arc times measured in single-phase reclosing tests have shown a considerable dispersion around the average value, a high standard deviation, due to variation of physical factors. In this context, it is usually used as a safe DT of three times the average, about 1.5 to $2 \mathrm{~s}$. The transient stability of the extra high voltage (EHV) TL is threatened by safe-long single-phase reclosing DTs, only because in unfavorable circumstances, the secondary arcs can last between 1.5 and $2 \mathrm{~s}$ [5].

Besides that, currently, there are various automatic reclosing systems, especially high-speed and time-delayed. However, most of reclosing algorithms are based on time-delay. In this case, the breaker is being closed after an intentional time-delay, which is longer than what is considered for deionization of the arc [12]. In this case, it is performed regardless of the fault type (permanent or temporary). However, in this case, there is no guarantee if the arc is extinguished at the moment of reclosing for temporary fault. Thus, there could be a risk of reclosing for permanent fault cases, which is considered as unsuccessful reclosing [13-15]. It is necessary to identify the fault type. On the contrary, high-speed algorithms reclose the breaker with a delay which is the minimum time for deionization of the arc. Based on the IEEE Standard C.37. 104-2012 guide [16], in order to have successful operations at auto-reclosing attempts identifying permanent or temporary faults, it is suggested to consider high-speed reclosure algorithms.

In addition, it is necessary to indicate that the single-phase reclosing is widely used and disabled in different continents due to the danger of the unsuccessful operation of traditional reclosing algorithms [17]. The main reason for the application of single-phase reclosing is related to increasing the power transfers capacity of the TL and the stability of EPS [18-23].

Based on what has been mentioned above, it is imperative to do research about the automatic reclosing in order to identify permanent and temporary faults, thus, in this research, a new automatic reclosure algorithm based on multivariable analysis and support vector machine (SVM) is proposed. The main contribution of the proposed single-phase reclosing relay algorithm is to acceptably identify the fault type, i.e., permanent or temporary, by using a simple mathematical procedure compared to the wavelet transform, which has been traditionally used to develop protection algorithms. This work then is divided into different sections as follows: a bibliographic review about automatic reclosure is given in the second section. The mathematical bases and the proposed algorithm are included in the third section. The simulation of the EPS and arc faults is presented in the fourth section. Main results are included in the fifth section. The autoreclosure flowchart is shown in the sixth section, and finally, the main conclusions of this research are presented in the last section.

\section{Bibliographic Review about Arcing Faults on TLs}

A primary arc is formed when an arcing fault occurs on TLs. It remains during the fault condition until the breakers open. After the breaker's tripping, the secondary arc appears being sustained by the mutual coupling between the faulted phase and the healthy phases or phase. In this context, 
different algorithms useful to identify permanent and temporary faults have been proposed using several mathematical tools. Those works are summarized as follows:

In Reference [24], a technique based on the analysis of harmonics spectrum of the faulted phase voltage is proposed. Using the amplitude of the second, third and fifth harmonic of the faulted phase voltage, permanent and temporary faults are identified. To detect the extinction of the secondary arc, the DC component is used due to the asymmetry of the recovery voltage and, the Wavelet Transform (WT) method is used to analyze those signals by means of the db6 as a mother wavelet. However, the determination of proper threshold value for distinguishing both types of faults are not clearly explained or well defined.

It is also possible to find the discrete wavelet transform (DWT) and the wavelet singularity considering several mother wavelets to classify the fault type [25-34]. Although those methods have acceptable behavior, their function and reliability are influenced by different conditions and parameters that must be chosen appropriately. For example, to determine the fault type, an index based on the normalized energy from decomposition levels 1 to 14 must be tested empirically. As an improvement, the DWT in combination with other techniques have been used, where a threshold adjustment is usually needed which depends directly on a trial and error procedure $[35,36]$.

Regarding autoreclosure schemes, in References [37,38], the conventional single-pole automatic reclosure (SPAR) algorithms are introduced; which are based on the RMS value of the faulted phase and a DT. However, in some cases, that value may not be enough before the secondary arc is extinguished. As a new technique, in Reference [39], the derivate of the voltage amplitude and the angle of the faulted phase is used for classifying fault type. In that method, the least error square (LES) method is used to calculate the derivate. However, its behavior depends on the sampling rate and it can sensitivity to outliers, which could increase the processing and calculation times. It is possible to find in References [40-48], different methods based on the frequency analysis, especially harmonic values of the faulted phase. In those methods, by using a discrete Fourier transform (DFT), several indexes are calculated. However, it is clear that the DFT has to be used with sampled signals minimum of one cycle. Besides that, these techniques can erroneously analyze the harmonics when conditions of fault with different oscillations are present. Moreover, in Reference [49] the evaluation of transient energy of the system is used by the proposed technique. Thus, spectral energy (SE) is used to predict the reclosure time.

The use of artificial intelligent had also been probed, fuzzy logic (FL) is used in Reference [50] to create a comparator that has as inputs the ratio between the voltage of the faulted phase and mutual inductance voltage and between capacitance coupling voltage and mutual inductance voltage. For the inputs of various intelligent classifiers, the signal features are extracted using FT, FFT and WT to decompose the voltage waveforms. In this context, in References [51,52], two processes are explained, one to obtain features of faults using FFT, and the other one, to identify faults prior to reclosing employing artificial neural networks (ANN). In addition, it is clear that these previous methods usually provide relevant information of stationary signals. Hence, the behavior of permanent and temporary faults may lead to inaccurate results when using the FT, FFT and WT. Therefore, in order to analyze arcing fault signals signal processing techniques (SPT) more advanced than FT and WT are needed. In Reference [53], the ANN was employed again, using as inputs those coefficients obtained with the Gabor transform (GT) as a technique of signal processing. In this case, this technique is a special case of the WT, which uses a Gaussian shape as a mother function. Therefore, the fault signals must be as similar as possible to the Gaussian shape.

According to the above mentioned, different algorithms to identify permanent and temporary faults on TLs are proposed. All of them using different SPT such as WT and FT. However, in the automatic reclosure environment, the algorithm must be accurate, i.e., it cannot depend on a trial and error technique. It is well known that the WT tool is very complex due to the wavelet mother selection and, has several inconveniences which are studied and presented in Reference [36]. 
The goal of this paper was to propose a new automatic reclosure algorithm based on multivariable analysis, which was used to optimally determine the permanent and temporary faults relevant information and, to classify the fault types using SVM. Unlike the proposed different autoreclosure schemes, the novelty of this scheme was that only a simple convolution process between permanent or temporary fault and the eigenvectors was used, without having to determine threshold levels or energy spectrums like other techniques i.e., avoiding trial and error results. In addition, the proposed algorithm in this work was tested with a signals database in different locations along the TL, including the accurate representation of the first and second arcs.

\section{Mathematical Bases of the Proposed Algorithm}

Principal component analysis (PCA) is an important and very useful tool to extract the most relevant information from a group of signals obtaining newer and simpler ones called principal components (PCs), as a linear combination of the original variables [54]. In this way, it is possible to generate a database smaller than the original. Thus the calculus of variance-covariance matrix $\mathbf{R}$ is fundamental to apply this technique, and with these values, the eigenvalues and eigenvectors are calculated.

With the original fault signals denoted in this research by Xtrai, the matrix $\mathbf{X}$ is formed, which is normalized, the process consists in scaling the matrix to have a maximum $(+1)$ and minimum $(-1)$ value. In this paper, the permanent and temporary fault signals are represented by a data-row vector $X_{\text {trai }}$ of length $p=4000$. Later on, each value of the matrix $\mathbf{X}$ is divided to its maximum absolute data denoted by Xmax [54].

$$
\begin{aligned}
X_{\text {trai } 1} & =\left[\begin{array}{llllll}
X_{1,1} & X_{1,2} & X_{1,3} & \ldots & X_{1, P}
\end{array}\right] \\
X_{\text {trai } 2} & =\left[\begin{array}{llllll}
X_{2,1} & X_{2,2} & X_{2,3} & \ldots & X_{2, P} &
\end{array}\right] \\
X_{\text {trai3 } 3} & =\left[\begin{array}{llllll}
X_{3,1} & X_{3,2} & X_{3,3} & \ldots & X_{3, P}
\end{array}\right] \\
X & =\left[\begin{array}{ccccc}
X_{11} & X_{12} & \ldots & X_{1 P} \\
X_{21} & X_{22} & \ldots & X_{2 P} \\
\vdots & \vdots & \ddots & \vdots \\
X_{m 1} & X_{m 2} & \ldots & X_{m p}
\end{array}\right]
\end{aligned}
$$

where $X_{\text {traip }}$, represents the training fault signal number that forms the matrix $\mathbf{X}$ and $m$ corresponds to the signal and $p$ is the variable number.

Since this new matrix, its mean value $\bar{Q}$ was calculated, and with all those data, the $\mathbf{R}$ matrix was calculated.

$$
\begin{aligned}
& R=\frac{\sum_{i=1}^{m}\left(Q_{i}-\bar{Q}\right)\left(Q_{i}-\bar{Q}\right)}{(m-1)} \\
& R=\left[\begin{array}{cccc}
\operatorname{cov}_{1,1} & \operatorname{cov}_{1,2} & \ldots & \operatorname{cov}_{1,4000} \\
\operatorname{cov}_{2,1} & \operatorname{cov}_{2,2} & \ldots & \operatorname{cov}_{2,4000} \\
\vdots & \vdots & \ddots & \vdots \\
\operatorname{cov}_{4000,1} & \operatorname{cov}_{4000,2} & \ldots & \operatorname{cov}_{4000,4000}
\end{array}\right]
\end{aligned}
$$

After that, by using the matrix $\mathbf{R}$, their eigenvalues, $\gamma$, and eigenvectors, $v$, were calculated. Both had the same size:

$$
\mathrm{U}_{m, n}=\left[\begin{array}{lllll}
\mathrm{U}_{m, 1} & \mathrm{U}_{m, 2} & \mathrm{U}_{m, 3} & \ldots & \mathrm{U}_{p, p}
\end{array}\right]^{T} \text { peigenvector }
$$




$$
\begin{aligned}
& \mathrm{U}=\left[\begin{array}{cccc}
u_{1,1} & u_{1,2} & \ldots & u_{1,4000} \\
u_{1,2} & u_{2,2} & \ldots & u_{2,4000} \\
\vdots & \vdots & \ddots & \vdots \\
u_{4000,1} & u_{4000,2} & \ldots & u_{4000,4000}
\end{array}\right] \\
& \Psi_{m n}=\left[\begin{array}{lllll}
\Psi_{1} & \Psi_{2} & \Psi_{3} & \ldots & \Psi_{p}
\end{array}\right]^{T} \text { peigenvalue } \\
& \Psi=\left[\begin{array}{ccccc}
\Psi_{1,1} & 0 & & \ldots & 0 \\
0 & \Psi_{2,2} & & \ldots & 0 \\
\vdots & \vdots & \ddots & & \vdots \\
0 & 0 & \ldots & \multicolumn{2}{c}{\Psi_{4000,4000}}
\end{array}\right]
\end{aligned}
$$

where $p$ is the number of variables and $T$ the transposed.

Finally, based on these eigenvectors, the principal components PC were calculated as follows:

$$
P C=[X] *[U]
$$

Based on the previous equation, it is clear that the new matrix PC is calculated by multiplying the original matrix $\mathbf{X}$ by the eigenvectors' matrix $\mathbf{U}$, obtaining a $4000 \times 4000$-sized matrix $\mathbf{P C}$. However, because matrix $\mathbf{U}$ is considered as a transformation matrix, it has the advantage that the data is reorganized based on its variability. Hence, in order to determine which data of permanent and temporary faults registered by the protection relay had major information quantity, an index constituted by the sum of the eigenvalues was used. The first eigenvalue was related to the first eigenvector, the second eigenvalue was related to the second eigenvector, and so on. In this paper, the index value denoted by Ivar must be longer than the threshold value denoted by thv, which in this research was $90 \%$, approximately. Therefore, after a detailed analysis of eigenvalues, by using the first twenty-four PCs, a variance value longer than thv was obtained. The next equations were used for this purpose:

$$
\text { Ivar } \%=\frac{\Psi_{1}+\Psi_{2}+\ldots+\Psi_{24}}{\sum_{i=1}^{n} \Psi_{i}=\Psi_{1}+\Psi_{2} \ldots \Psi_{p}} x 100
$$

In this context, the first twenty-four PCs were calculated as follows:

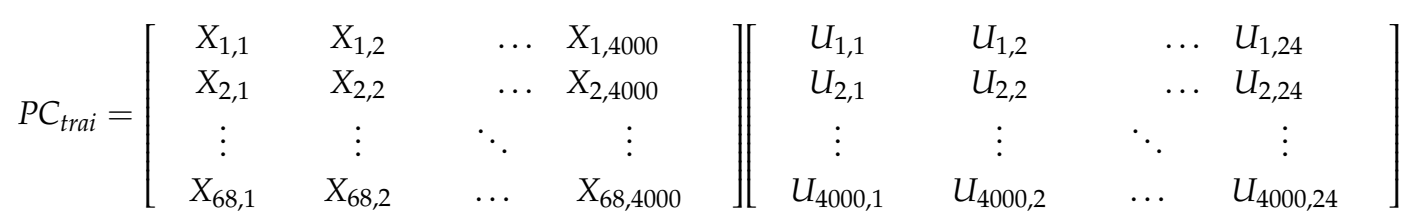

In this research, it is possible to see that the proposed methodology transforms the original row vector $1 \times 4000$ to $1 \times 24$, approximately. Therefore, a factor of reduction of 4000/24 166 in the original signals was obtained.

Besides that, protection relay algorithms are related to an analysis-classification problem of fault signals. In the first instance of this research, the permanent and temporary faults were analyzed by using some PCA, those new signals were used as input vectors in the classifier based on SVM (see Section 5.2).

\section{Theoretical Modeling and Simulation of Arc and EPS Used}

\subsection{Arc}

When an arcing fault occurs in the system, a primary arc is formed and is presented during fault duration until the moment when the breakers open. After the tripping of the breaker, the secondary arc appears and it is sustained by the mutual coupling between the faulted phase and the healthy phases. 
Considering the nature of arcing faults, the arcs (primary and secondary) have to be represented as accurately as possible [16,55]. In fact, in Reference [55] it has been proven that the switching arc theory can be applied to model an unconstrained long fault arc in the air.

The primary arc model could be implemented by using the one developed by Kizilcay. This model, developed by Mustafa Kizilcay and others, is time-dependent, it describes the dynamic behavior of the arc through the air when a fault occurs. It also takes into consideration the dynamic interaction of the arc with the remaining electrical circuit, and it is based on the balance of energy of the arc column $[55,56]$. This model describes the arc in the air by means of the differential equation of the conductance of $\operatorname{arc} g$, written as:

$$
\frac{1}{g} \frac{d g}{d t}=\frac{1}{\tau}(G-g)
$$

where $g$ is the conductance variable with time, $\tau$ is the time constant and $G$ is the stationary conductance of the arc, physically interpreted as the value of constant conductance. If the conditions of the primary arc were sustained for a long period of time from an external source and can be represented by the following function:

$$
G=\frac{|i|}{\left(\mu_{0}-|i| r_{0}\right) l}
$$

where: $\mu_{0}$ is a constant voltage and is defined in per unit length, $r_{0}$ is the resistive component of the arc in per unit length, $i$ is the arc current, and $l$ is the length of the arc which may vary with time.

As regards the secondary arc, its behavior has been studied since the last decade, without having an exact model to date that gathers all the factors that contribute to it because generating a secondary arc in the laboratory to measure its parameters is a very difficult task since it is a very fast phenomenon that depends mainly on the primary arc. Considering the secondary arc, all the references found simulate it by using the technique proposed by Goldberg [57]. However, this model is based on the one developed by Jones [58,59], which is based on an empirical approach of two features, described as follows:

Features of the arc's conductivity:

This characteristic is used when the arc conducts current, which occurs when the magnitude of the voltage across the arc exceeds the resisting voltage before starting to drive. The volt-ampere characteristics of the model for a range of currents between 1 and $55 \mathrm{~A}$. The constant value of the voltage parameter $V_{p}$ is given by:

$$
V_{p}=75 I_{p}^{-0.4}
$$

where $I_{p}$ is the peak value of the secondary arc current. It was assumed that the arc resistance was zero $(0)$, taking into account that the equivalent resistance of the ascending and descending parts is a function of the length of the arc and the variation of time.

Feature of the re-ignition voltage of the arc:

This characteristic was applied to obtain the voltage that resists the arc before starting to conduct electricity, that is, the voltage of the dielectric recovery (in this case air) when it was not conducting. The expression that defines this voltage can be approximated by the following equation:

$$
\left|V_{r}\left(t_{r}\right)\right|=\left[5+1620 \frac{T_{e}}{2.15+\left|I_{s}\right|}\right]\left(t_{r}-T_{e}\right) h\left(t_{r}-T_{e}\right)
$$

In practice, the time of extinction of the secondary arc depends on the variation of the arc length. For relatively low wind speed values between $0-1 \mathrm{~m} / \mathrm{s}[60]$, this variation as a function of time can be approximated by:

$$
\frac{l_{s}\left(t_{r}\right)}{l_{0}}=\left\{\begin{array}{cc}
1 & t_{r} \leq s e g \\
10 t_{r} & t_{r}>\operatorname{seg}
\end{array}\right\}
$$

where $l_{s}\left(t_{r}\right)$ is the length of the arc and so is the initial length of the arc, both in $\mathrm{cm}$. 
According to Equations (18) and (19), the reignition voltage of the arc is obtained by the following equation:

$$
\left|V_{\text {arcw }}\left(t_{r}\right)\right|=\left|V_{r}\left(t_{r}\right)\right| l_{r}\left(t_{r}\right)
$$

If the voltage imposed by the supply system was greater than the restarting voltage when the secondary arc crosses zero, the arc was kept in a conduction state, otherwise, it remained in a partial or final condition.

\subsection{Signals and Simulated EPS}

In this research, ATP [61] was used for modeling a typical $500 \mathrm{kV}$ EPS, which consisted of two areas connected by a $350 \mathrm{~km} \mathrm{TL}$ and breakers that are activated when the fault occurs; see Figure 3. In this case, voltage sources are considered. For the purpose of modeling the TL, a model proposed by J. Marti was employed [62]. In order to perform an acceptable behavior analysis, models of primary and secondary arcs were used for simulation together with various permanent and temporary faults, which are simulated along different sections of the TL. In this context, for the cases of study, the TL was divided into thirty-four parts as $10 \mathrm{~km}$ in each section. Therefore, the permanent or temporary fault occurrence at $10 \mathrm{~km}, 20 \mathrm{~km}, 30 \mathrm{~km}, 40 \mathrm{~km}$, and so on up to $340 \mathrm{~km}$ distances from the location of the protection relay can be simulated. The single-phase-to-ground faults were applied to the TL using a single-phase breaker. Therefore, it was possible to perform appropriate operations for permanent or temporary faults. The sampling rate for recording the ATP signals was $10 \mathrm{kHz}$. These signals were loaded to Matlab to make different analysis and algorithms. An original data matrix comprised by 68 fault signals evaluated by relay $\mathrm{R} 1$ at bus $\mathrm{M}$ was used in the training process, which is represented in this paper by a matrix of size $68 \times 4000$, where each permanent or temporary fault was composed by 4000 points or variables.

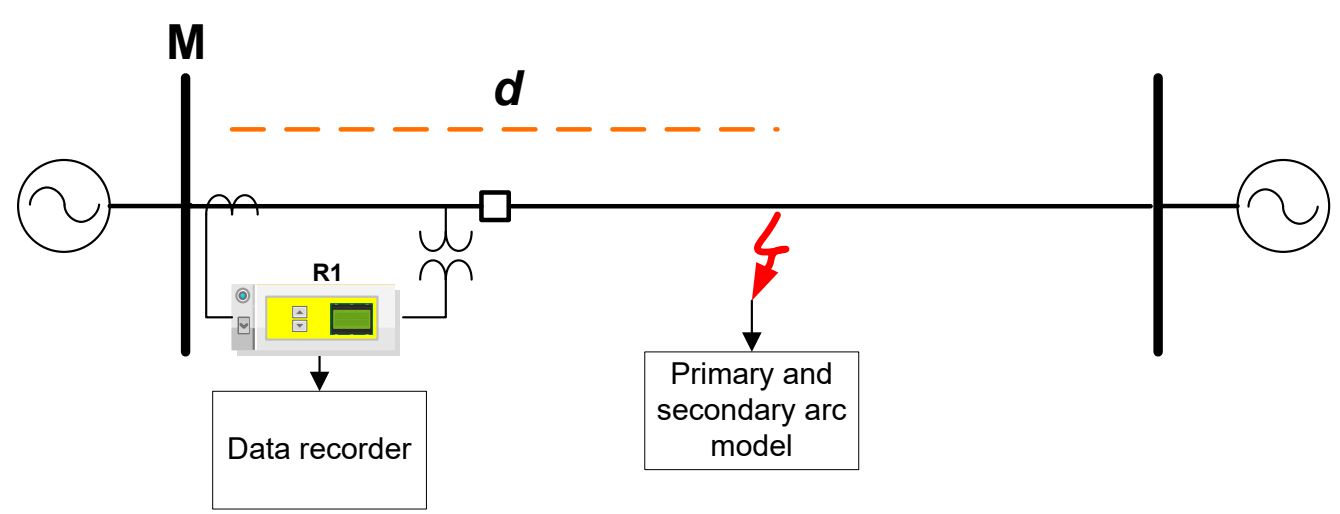

Figure 3. Electric power system used.

As regards the waveforms of temporary fault, the voltage waveform is shown as time function for the case of a temporary fault measured on the faulted phase in Figure 4, when after a time the fault is disconnected and the waveform is restored. For this particular case, the fault inception time was $\mathrm{t}=0.1 \mathrm{~s}$ (A) which was the moment at which the primary arc appears. Then, when the fault appeared, and the detection and clearing relay operated to open the faulted phase, the secondary arc was formed at $t=0.2 \mathrm{~s}(\mathrm{~B})$; this fault, the secondary arc, continued during a period of time, and then, it was finally extinguished and re-striked at $0.55 \mathrm{~s}(\mathrm{C})$ due to the characteristic high-frequency components in the waveform. 


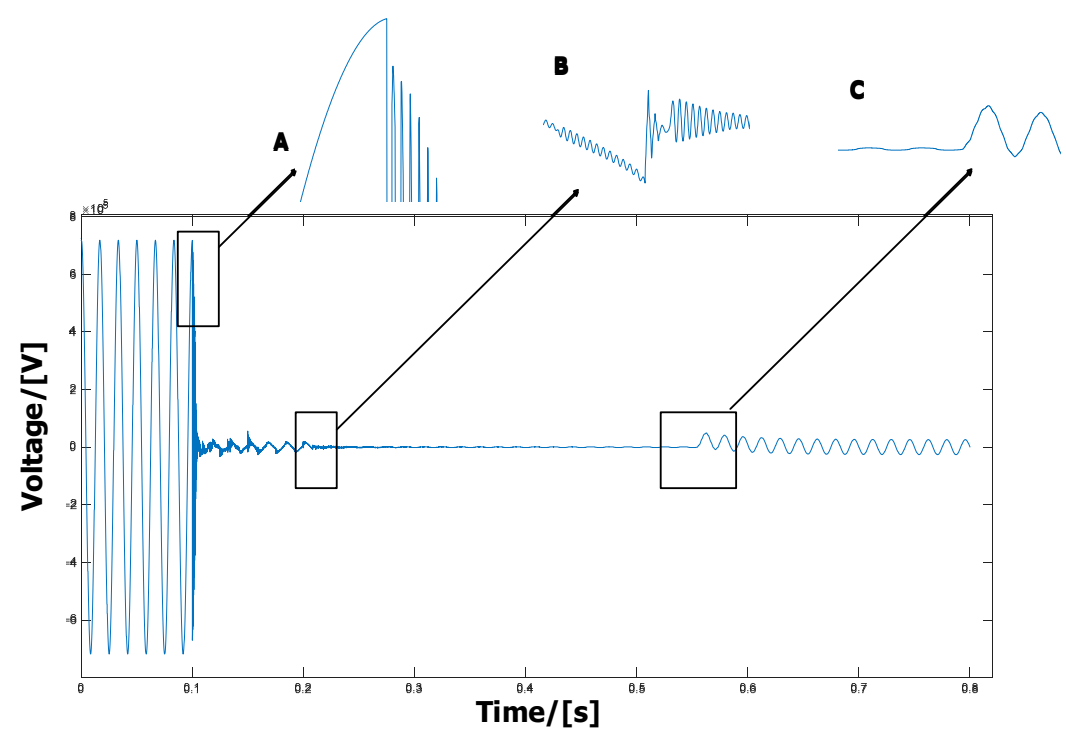

Figure 4. Voltage signal due to the temporary fault.

During this last stage, from point $B$ to point $C$, it was noticeable in the line a small and normal system frequency voltage sinusoidal component, which was caused by the electrostatic coupling between the two healthy phases and the faulted phase.

On the contrary, the fault voltage of the permanent fault was similar to the previous one, but in this case, the secondary arc disappeared, as can be appreciated in Figure 5. It represented a voltage waveform due to a permanent single-phase fault.

In the first part, the transients obtained in the primary arc were present, but the characteristics of the secondary arc were absent. Thus, after the breakers of the circuit have acted due the presence of the fault, a small system frequency voltage induced onto the tripped line is presented, whose magnitude depended directly not only on the accuracy and on how well the two healthy phases of the TL were coupled to the faulted phase but also on the fault impedance. For that reason, in this process of reconnection, the size of the voltage mentioned was determined.

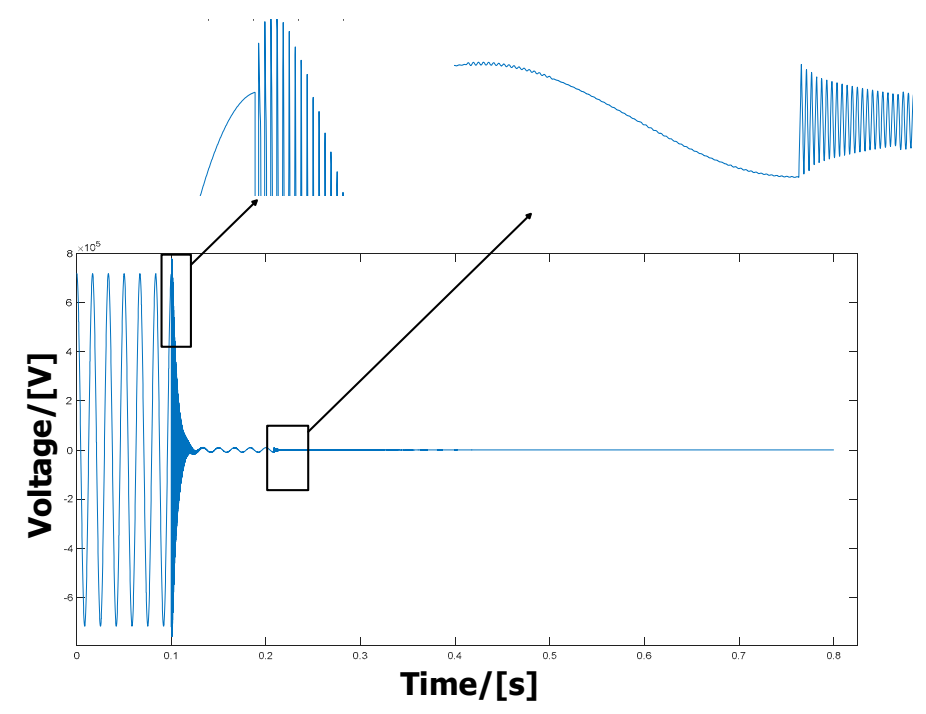

Figure 5. Voltage signal due to the permanent fault.

\section{Results}

By using the mathematical formulation presented in Section 2 to the permanent and temporary faults of training, coefficients of PC were computed by correlating these fault signals with the calculated 
eigenvectors. The study shows that the analysis of PCs generates 24 PCs, shown in Table 1, which were analyzed as follows:

Table 1. Principal Component Analysis (PCA) vector values obtained.

\begin{tabular}{|c|c|c|c|c|c|c|c|c|c|c|c|c|}
\hline \multirow{2}{*}{$\begin{array}{c}\text { Vector } \\
\text { Component }\end{array}$} & \multicolumn{12}{|c|}{ PCA } \\
\hline & 1 & 2 & 3 & 4 & 5 & 6 & $\ldots$ & 20 & 21 & 22 & 23 & 24 \\
\hline 1 & -0.001 & -0.144 & -0.034 & 0.065 & 0.190 & 0.094 & $\cdots$ & -0.001 & 0.072 & 0.019 & -0.003 & 0.005 \\
\hline 2 & 0.000 & -0.148 & 0.075 & 0.121 & 0.340 & 0.067 & $\ldots$ & -0.014 & 0.025 & 0.016 & 0.063 & -0.019 \\
\hline 3 & -0.001 & -0.156 & 0.064 & 0.115 & 0.301 & 0.179 & $\ldots$ & -0.075 & 0.078 & 0.067 & 0.156 & -0.075 \\
\hline 4 & -0.001 & -0.173 & 0.033 & 0.148 & 0.276 & 0.252 & $\ldots$ & -0.169 & 0.151 & -0.001 & 0.008 & 0.012 \\
\hline 5 & -0.001 & -0.222 & 0.056 & 0.207 & 0.356 & 0.251 & $\ldots$ & 0.017 & -0.178 & -0.004 & 0.034 & -0.127 \\
\hline 6 & -0.001 & -0.158 & 0.182 & 0.106 & 0.294 & 0.192 & $\ldots$ & -0.111 & 0.021 & 0.247 & -0.036 & -0.092 \\
\hline 7 & -0.001 & -0.150 & 0.176 & 0.192 & 0.345 & 0.164 & $\ldots$ & -0.108 & 0.028 & -0.053 & 0.166 & 0.005 \\
\hline 8 & -0.001 & -0.076 & -0.076 & 0.149 & 0.399 & 0.206 & $\ldots$ & -0.128 & 0.063 & -0.042 & 0.094 & -0.033 \\
\hline 9 & -0.001 & -0.076 & -0.094 & -0.011 & 0.452 & 0.246 & $\ldots$ & 0.035 & -0.020 & -0.146 & 0.147 & 0.247 \\
\hline 10 & 0.000 & -0.095 & -0.051 & 0.147 & 0.396 & 0.212 & $\ldots$ & -0.036 & 0.078 & -0.015 & 0.059 & 0.000 \\
\hline 11 & -0.001 & -0.083 & -0.026 & 0.044 & 0.210 & 0.166 & $\ldots$ & -0.065 & -0.094 & 0.156 & 0.242 & -0.184 \\
\hline 12 & -0.001 & -0.112 & 0.020 & 0.171 & 0.179 & 0.353 & $\ldots$ & -0.026 & 0.033 & -0.052 & -0.108 & -0.027 \\
\hline 13 & 0.000 & -0.112 & 0.008 & 0.172 & 0.174 & 0.212 & $\ldots$ & -0.090 & 0.268 & 0.256 & 0.156 & -0.134 \\
\hline 14 & -0.001 & -0.101 & -0.014 & 0.166 & 0.185 & 0.241 & $\ldots$ & -0.054 & -0.045 & -0.221 & 0.239 & -0.222 \\
\hline 15 & -0.001 & -0.100 & -0.040 & 0.105 & 0.221 & 0.241 & $\ldots$ & -0.093 & -0.186 & -0.094 & 0.046 & 0.121 \\
\hline 16 & -0.001 & -0.084 & -0.070 & 0.119 & 0.243 & 0.265 & 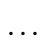 & -0.220 & 0.115 & 0.251 & 0.069 & 0.072 \\
\hline 17 & -0.001 & -0.066 & -0.094 & -0.223 & 0.249 & 0.150 & $\ldots$ & -0.094 & 0.124 & 0.052 & 0.085 & -0.018 \\
\hline 18 & -0.001 & -0.100 & -0.039 & -0.091 & 0.212 & 0.305 & $\ldots$ & 0.115 & 0.156 & 0.011 & 0.121 & -0.159 \\
\hline 19 & 0.000 & -0.145 & 0.075 & 0.108 & 0.173 & 0.095 & $\ldots$ & -0.088 & 0.291 & 0.011 & 0.227 & -0.211 \\
\hline 20 & 0.000 & -0.147 & 0.073 & 0.107 & 0.183 & 0.092 & $\ldots$ & -0.092 & 0.085 & 0.001 & 0.009 & 0.039 \\
\hline$\ldots$ & $\ldots$ & $\ldots$ & $\ldots$ & & $\ldots$ & . & $\ldots$ & $\ldots$ & $\ldots$ & & & $\ldots$ \\
\hline$\ldots$ & $\ldots$ & $\ldots$ & $\ldots$ & $\ldots$ & $\ldots$ & $\ldots$ & $\ldots$ & $\ldots$ & $\ldots$ & $\ldots$ & $\ldots$ & $\ldots$ \\
\hline$\ldots$ & $\ldots$ & $\ldots$ & $\ldots$ & & & $\because$ & $\ldots$ & $\cdots$ & 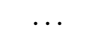 & & $\cdots$ & \\
\hline 44 & -0.238 & -0.079 & -0.037 & 0.159 & 0.492 & 0.297 & $\ldots$ & 0.043 & 0.146 & -0.067 & 0.021 & 0.045 \\
\hline 45 & -0.004 & -0.088 & -0.010 & 0.072 & 0.232 & 0.245 & $\ldots$ & -0.002 & -0.157 & 0.108 & 0.178 & -0.275 \\
\hline 46 & -0.200 & -0.067 & -0.118 & 0.288 & 0.331 & 0.304 & $\ldots$ & -0.067 & 0.080 & -0.170 & -0.128 & 0.052 \\
\hline 47 & -0.224 & 0.016 & 0.036 & 0.310 & 0.252 & 0.251 & $\ldots$ & -0.147 & 0.395 & 0.093 & 0.162 & -0.026 \\
\hline 48 & -0.208 & -0.127 & -0.026 & 0.238 & 0.340 & 0.244 & $\ldots$ & -0.063 & 0.055 & -0.255 & 0.185 & -0.267 \\
\hline 49 & -0.150 & -0.034 & -0.043 & 0.211 & 0.377 & 0.335 & $\ldots$ & 0.098 & -0.114 & -0.088 & -0.102 & 0.287 \\
\hline 50 & -0.199 & -0.037 & -0.147 & 0.247 & 0.314 & 0.242 & $\ldots$ & -0.188 & 0.115 & 0.159 & -0.019 & 0.197 \\
\hline 51 & -0.048 & -0.047 & -0.203 & -0.284 & 0.416 & 0.166 & $\ldots$ & -0.060 & 0.236 & 0.001 & -0.019 & 0.124 \\
\hline 52 & -0.027 & -0.129 & -0.149 & -0.029 & 0.422 & 0.495 & $\ldots$ & 0.233 & 0.367 & -0.097 & 0.104 & -0.253 \\
\hline 53 & -0.025 & -0.087 & -0.033 & 0.075 & 0.319 & 0.123 & & -0.129 & 0.497 & 0.002 & 0.201 & -0.277 \\
\hline 54 & -0.259 & -0.144 & 0.148 & 0.125 & 0.214 & -0.026 & $\ldots$ & -0. & 0.214 & 0. & 0.095 & 0.188 \\
\hline 55 & -0.462 & -0.180 & -0.064 & & 0.496 & 0.166 & $\ldots$ & -0 . & 0.070 & 0.243 & 7 & 0.435 \\
\hline 56 & -0.158 & -0.081 & 0.055 & & 0.346 & 0.189 & $\ldots$ & -0.008 & 0.001 & 0.218 & 0.021 & 0.017 \\
\hline 57 & -0.389 & -0.099 & 0.032 & 0.187 & 0.333 & -0.012 & $\ldots$ & 0.053 & -0.080 & -0.216 & 0.036 & 0.072 \\
\hline 58 & -0.276 & -0.130 & -0.044 & 0.093 & 0.414 & 0.024 & $\ldots$ & -0.046 & 0.149 & -0.106 & -0.051 & -0.127 \\
\hline 59 & -0.168 & -0.130 & -0.069 & 0.153 & 0.536 & 0.210 & $\ldots$ & 0.043 & 0.333 & -0.003 & 0.120 & -0.011 \\
\hline 60 & -0.343 & -0.205 & 0.099 & 0.118 & 0.460 & 0.103 & $\ldots$ & 0.304 & 0.439 & -0.095 & 0.108 & -0.124 \\
\hline 61 & -0.628 & -0.196 & -0.060 & 0.221 & 0.386 & -0.168 & $\ldots$ & 0.254 & 0.209 & -0.249 & 0.037 & -0.195 \\
\hline 62 & -0.124 & -0.173 & 0.117 & 0.090 & 0.529 & 0.076 & $\ldots$ & -0.118 & 0.218 & -0.459 & 0.269 & -0.151 \\
\hline 63 & -0.132 & -0.163 & 0.042 & 0.002 & 0.318 & 0.083 & $\ldots$ & -0.129 & 0.124 & -0.298 & 0.282 & -0.105 \\
\hline 64 & -0.107 & -0.130 & 0.010 & -0.002 & 0.275 & 0.002 & $\ldots$ & -0.058 & 0.100 & -0.049 & 0.035 & 0.346 \\
\hline 65 & 0.006 & -0.182 & -0.016 & -0.007 & 0.547 & -0.144 & $\ldots$ & -0.040 & 0.209 & -0.040 & 0.268 & 0.198 \\
\hline 66 & -0.112 & -0.155 & -0.029 & -0.031 & 0.502 & 0.042 & $\ldots$ & -0.127 & 0.289 & 0.279 & -0.016 & 0.093 \\
\hline 67 & -0.118 & -0.017 & -0.013 & 0.048 & 0.280 & -0.052 & $\ldots$ & 0.036 & 0.229 & 0.268 & 0.177 & 0.074 \\
\hline 68 & -0.260 & -0.060 & 0.000 & -0.054 & 0.324 & -0.150 & $\ldots$ & -0.066 & 0.113 & 0.023 & 0.021 & 0.124 \\
\hline
\end{tabular}

\subsection{Analyzing PCA}

In this section, by using the data of the new matrix, the PCs were projected in different spaces in order to make an analysis of distinctive identification of permanent and temporary faults. On this context, Figures 6-10 show the representation of faults through the PCA. 
Figure 6 shows the distribution of permanent and temporary faults on the first two PCs. Thus, in Figure 6 the red colored points correspond to temporary faults. On the contrary, the blue colored points represent permanent faults. Besides that, based on Table 1, it is clear that for permanent faults, the first PC was not significant. Its value was very similar to zero. Unlike permanent faults, for temporary faults, the first PC was very significant. Based on what was previously said, it was clear that in this 2D space projection, some of the faults were clearly identifiable. However, some temporary faults were superimposed on the space of the permanent faults.

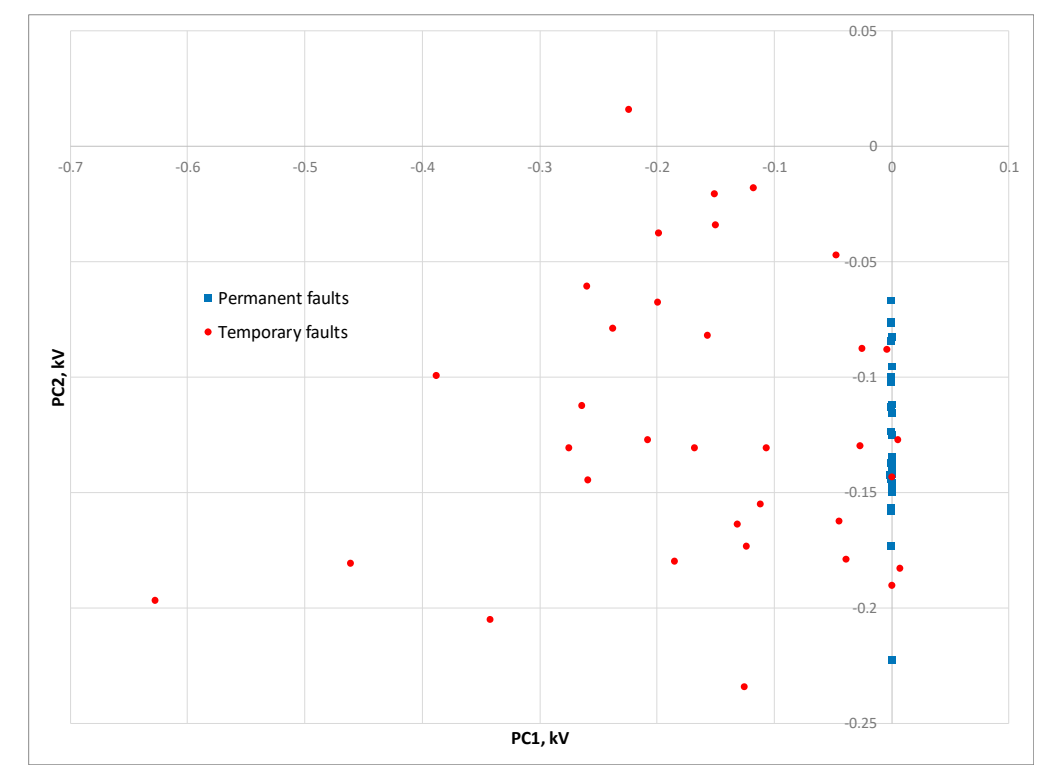

Figure 6. Permanent and temporary faults in the first and second subspace of Principal Components (PCs).

A similar analysis was developed considering the first and third PC. Figure 7 shows the representation of permanent and temporary faults on these axes. Similar to the previous case, that projection shows important information of the disposition of these faults.

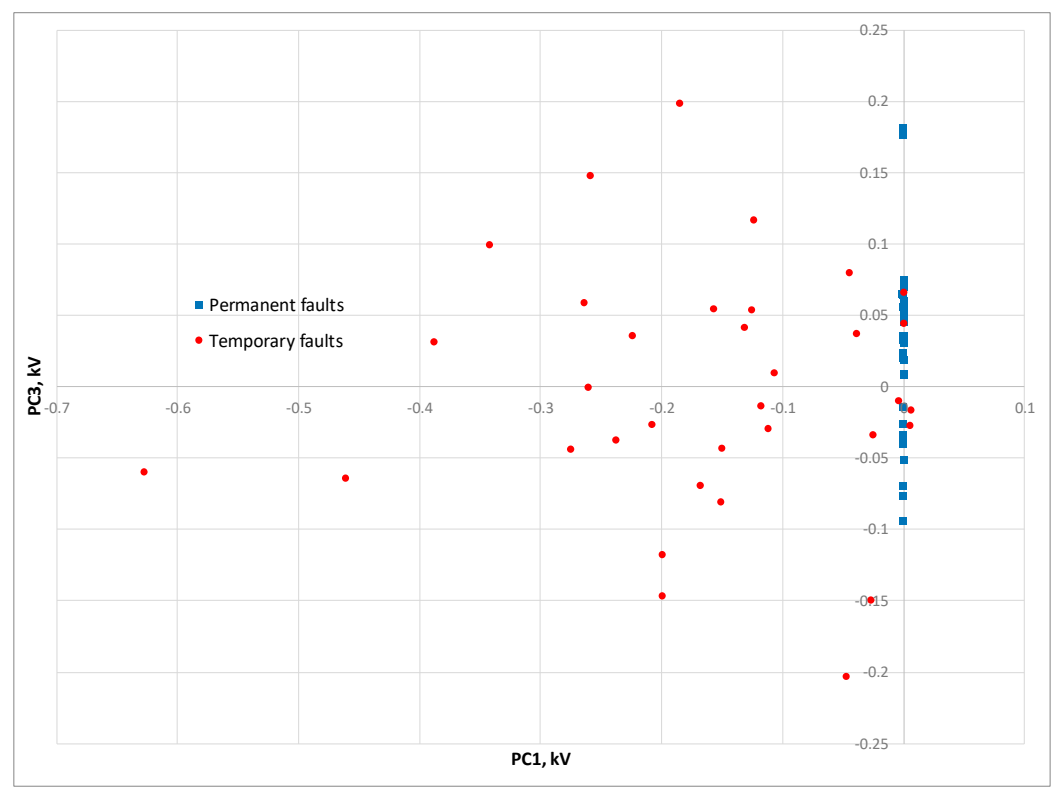

Figure 7. Permanent and temporary faults in the first and third subspace of PCs. 
From Figures 8-10, the study cases where the permanent and temporary faults projected on the second/fifth, sixth/ninth, and twenty-third/twenty-fourth PCs are presented. It is important to see that as the fault signals were projected onto the subsequent axes of the PCs, the dispersion or identification of the fault types was not very significant or clear. Thus, the first PC had a major variability of original fault signals.

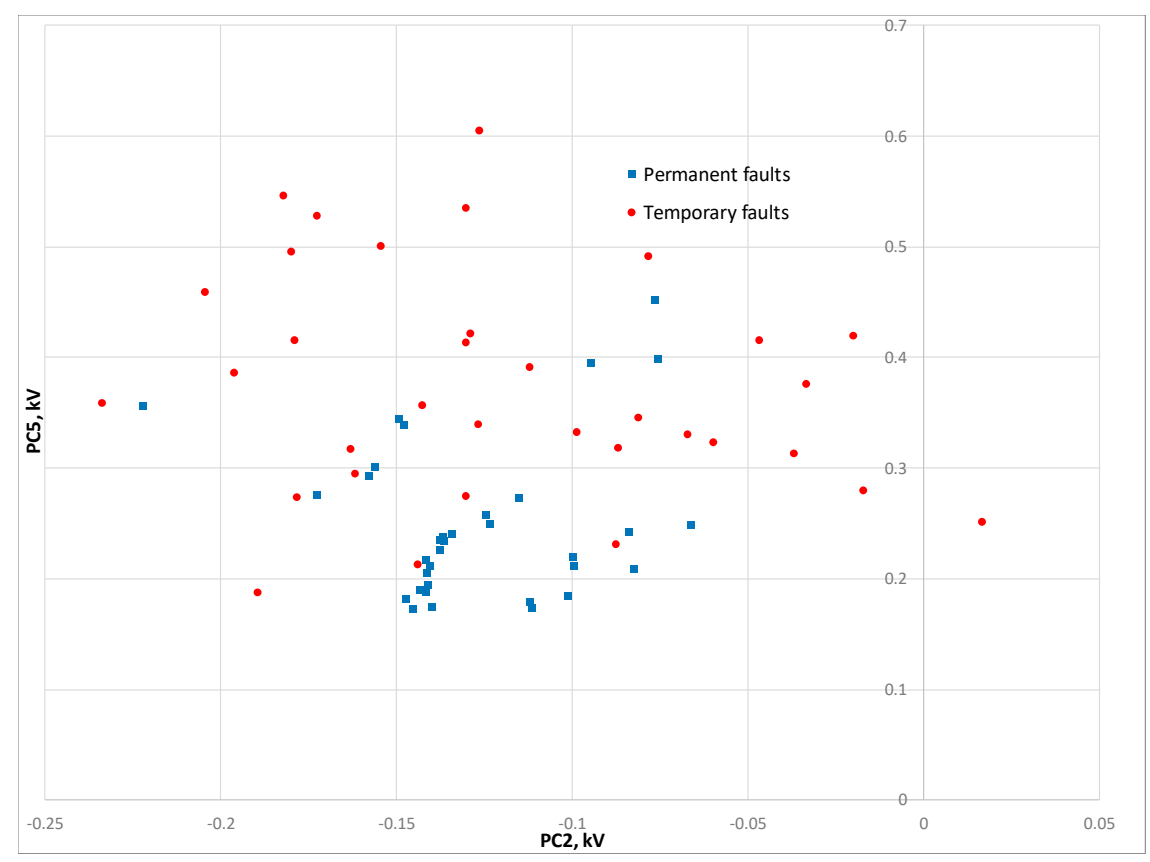

Figure 8. Permanent and temporary faults in the second and fifth subspace of PCs.

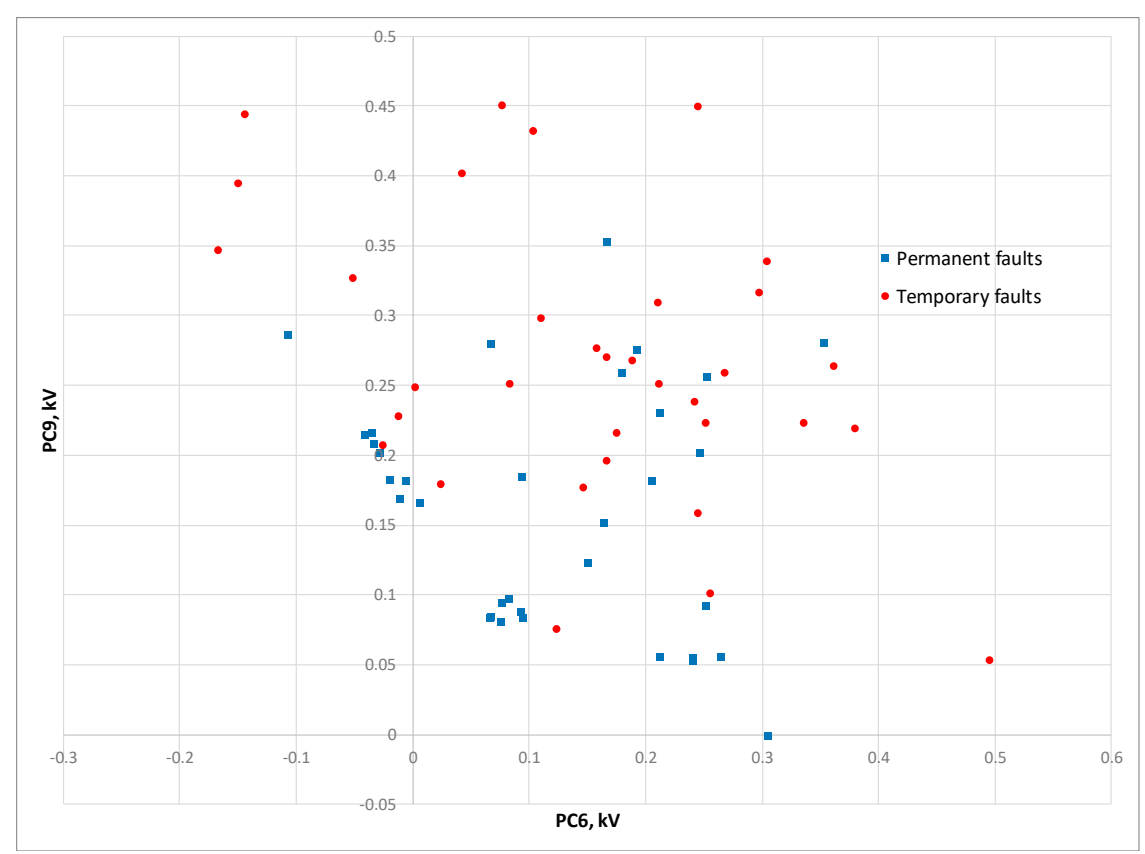

Figure 9. Permanent and temporary faults in the sixth and ninth subspace of PCs. 


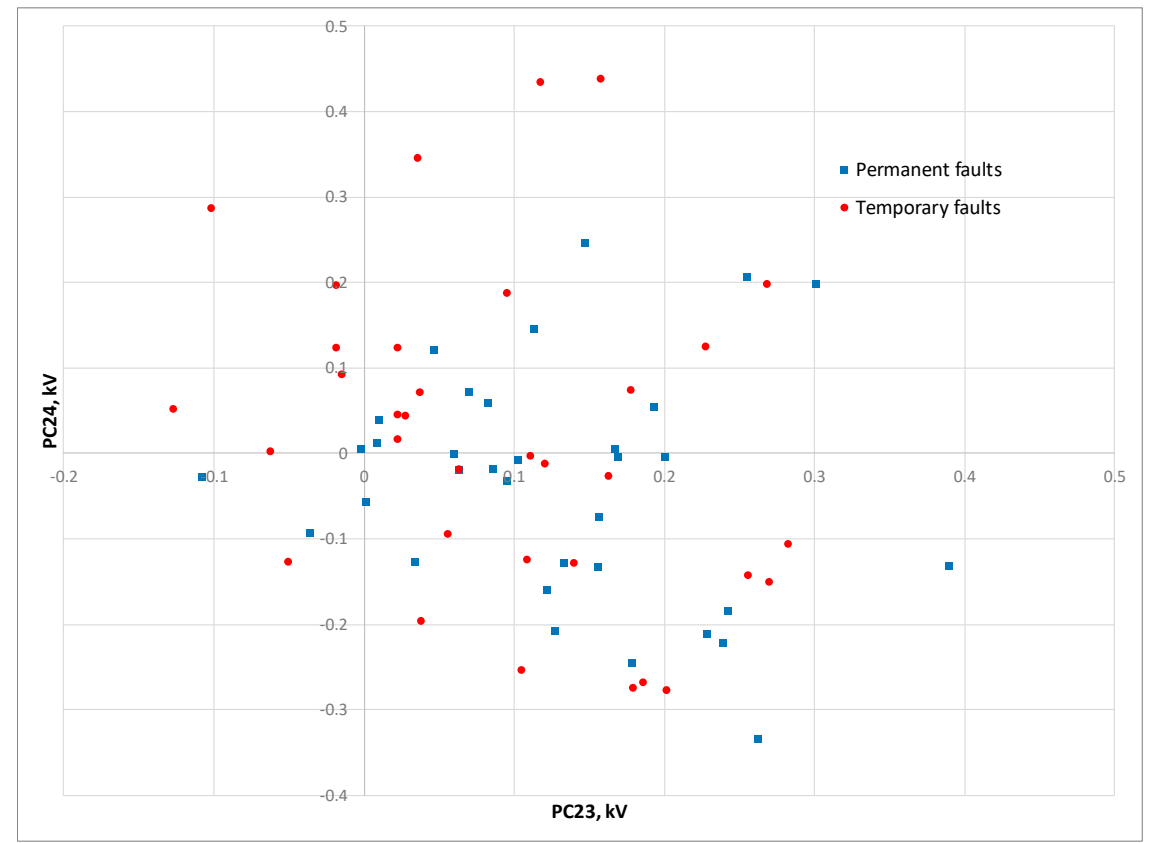

Figure 10. Permanent and temporary faults in the twenty-third and twenty-fourth subspace of PCs.

Besides that, as stated previously, the most important issue in order to propose novel protection relay algorithms was related to the mathematical tool used to analyze the original permanent and temporary fault signals. Thus, the multiresolution analysis (MRA) has widely been used for reclosing relay algorithms, which is processed through a mother function called wavelet mother and different levels of details of the discrete voltage samples recovered by the relay. However, in order to choose the best performance of MRA, a hard work of testing and error must be developed. For instance, Figure 11 shows the first two variables of the original fault signals. By analyzing this figure, it is clear that a distribution of the fault type is not possible. On the other hand, Figure 12 shows the coefficients of MRA projected to a 2D subspace. Similar to the previous case, it is possible to see that permanent and temporary faults are not well distinguished. Unlike the PCA, which can distinguish the fault type depending on the number of eigenvectors chosen (see Figure 6).

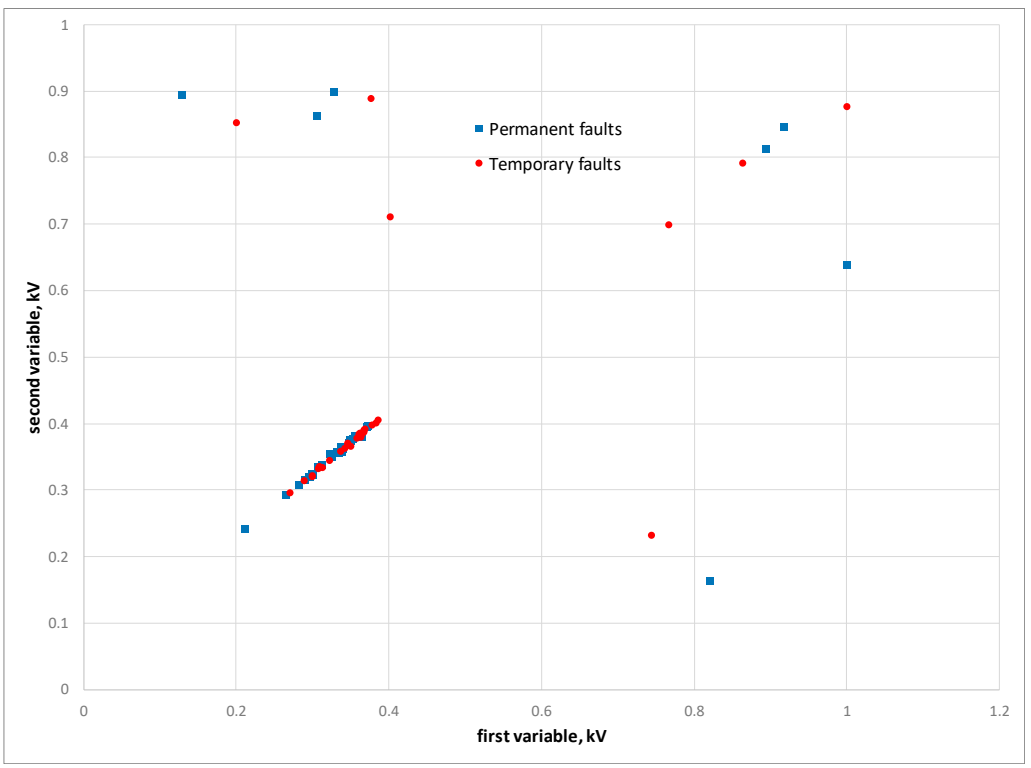

Figure 11. Permanent and temporary faults projected on the first two variables of the original faults' matrix. 


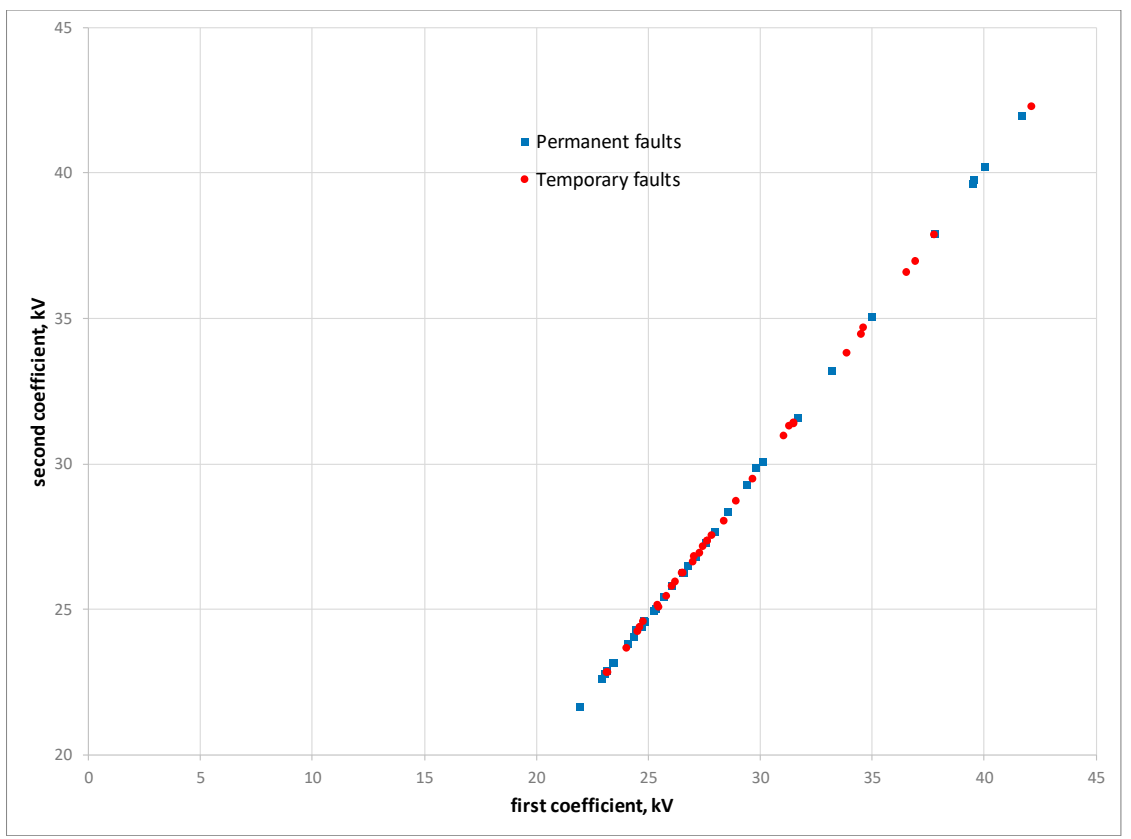

Figure 12. Permanent and temporary faults projected on the first two coefficients of the Multiresolution Analysis (MRA).

In addition, it is necessary to indicate that in the proposal of new protection algorithms, two scenarios must be clearly defined, off-line and on-line, respectively. The first one refers to the stage where the algorithm is trained, and the second stage refers to testing the algorithm with new fault signals different than those used in the training stage. In this sense, the proposed algorithm in this paper based on PCA had special features in order to test a new permanent or temporary fault signal in real time or on-line denoted in this paper by $X_{\text {test }}$. Thus, this new test signal only processed through the first twenty-four eigenvectors selected in the previous analysis, omitting to do all the mathematical processes presented in Section 3, which were used in the training process. Therefore, 72 new test signals measured by the relay $\mathrm{R} 1$ at bus $\mathrm{M}$ were used; 36 for permanent faults and 36 for temporary faults, where each permanent or temporary testing fault was composed by 4000 points or variables, that is $1 \times 4000$ row vector, which was processed by using those eigenvectors as follows:

The new test signal was divided into the maximum value of the original matrix $\mathbf{X}$ denoted in this research by $X_{\max }$, giving a new vector $X_{\text {norm }}$ as follows:

$$
X_{\text {norm }}=\frac{X_{\text {test }}}{X_{\max }}
$$

The vector $X_{\text {norm }}$ was subtracted from the mean vector $\bar{Q}$ of the original matrix $\mathbf{X}$

$$
R_{\text {test }}=X_{\text {norm }}-\bar{Q}
$$

Finally, $R_{\text {test }}$ was processed by using the first twenty-four eigenvectors that were determined in the training process (see Section 3). Thus, the PCs of the test signal were calculated as follows:

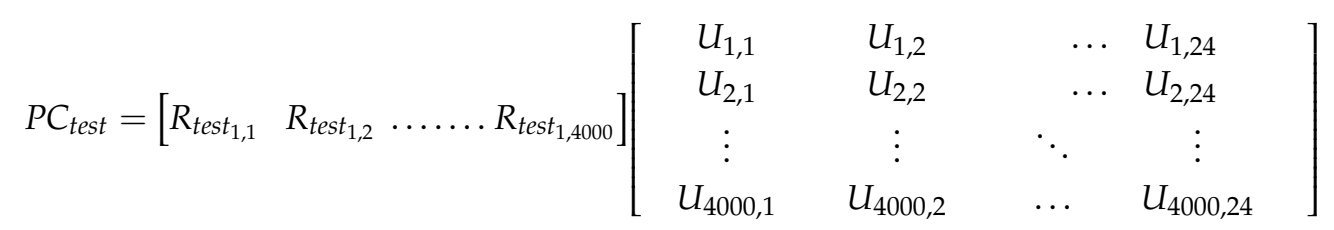




\subsection{Classification Based on a Support Vector Machine}

The information obtained in the PCA analysis was applied for studying any registered fault signal. The resultant matrix of this process was applied to SVM for classifying fault types based on the data set transformation from a specific dimension to a higher dimension by using a function called the kernel. It allowed working on a data set such as a linear problem.

An easier case occurred when a data set was separated using a hyper-plane represented as follows:

$$
w x_{i}+b=0
$$

where $w$ is a normal vector of plane and $b$ is a term called bias. However, each data set class was separated for a different hyper-plane, in such a way these allowed us to find an optimal hyperplane based on the margin between these two. In this context, the outputs of the PCs were used as inputs to the classifier based on SVM. Here, it was important to assign the necessary kernel parameters used in this method. The kernel type employed was the RBF which needed a gamma parameter. In this case, due to the number of variables and features of the signals, a gamma of 1.009 was established. This process gave an acceptable result, with a percentage of correct classification of $94.286 \%$. All the processes including obtaining PCA up to the classification were developed with other databases. In this other case, 72 test signals were used; 36 for permanent faults and 36 for temporary faults, respectively. Finally, by varying the gamma parameter, $97 \%$ of correct classification was obtained. Table 2 presents the results of some test signals.

Table 2. Obtained results of classification with Support Vector Machine (SVM).

\begin{tabular}{|c|c|c|c|c|c|c|c|c|c|c|c|c|}
\hline \multirow{2}{*}{$\begin{array}{c}\text { Vector } \\
\text { Component. }\end{array}$} & \multicolumn{8}{|c|}{ PCA } & \multicolumn{2}{|c|}{$\begin{array}{c}\text { Arcing First } \\
\text { Fault Confidence }\end{array}$} & \multicolumn{2}{|c|}{$\begin{array}{l}\text { Arcing Secondary } \\
\text { Fault Confidence }\end{array}$} \\
\hline & 1 & 2 & 3 & 4 & 5 & 6 & $\ldots$ & 22 & 23 & 24 & & \\
\hline 1 & 0.383 & -0.012 & -0.048 & 0.030 & -0.108 & -0.009 & $\ldots$ & -0.001 & 0.003 & 0.027 & 1 & 0 \\
\hline 2 & 0.383 & -0.012 & -0.048 & 0.030 & -0.110 & -0.011 & $\ldots$ & -0.003 & 0.004 & 0.023 & 1 & 0 \\
\hline 3 & 0.383 & -0.013 & -0.049 & 0.030 & -0.109 & -0.007 & $\ldots$ & 0.000 & 0.003 & 0.034 & 1 & 0 \\
\hline 4 & 0.384 & -0.012 & -0.050 & 0.030 & -0.115 & -0.011 & $\ldots$ & 0.001 & 0.002 & 0.025 & 0 & 1 \\
\hline 5 & 0.384 & -0.011 & -0.057 & 0.028 & -0.115 & -0.017 & $\ldots$ & 0.004 & -0.009 & 0.019 & 1 & 0 \\
\hline 6 & 0.386 & -0.016 & -0.055 & 0.029 & -0.121 & -0.017 & $\ldots$ & 0.003 & -0.005 & 0.020 & 1 & 0 \\
\hline 7 & 0.386 & -0.014 & -0.052 & 0.039 & -0.116 & -0.028 & $\ldots$ & 0.011 & 0.015 & 0.028 & 1 & 0 \\
\hline 8 & 0.386 & -0.016 & -0.055 & 0.032 & -0.125 & -0.012 & $\ldots$ & -0.001 & -0.003 & 0.013 & 1 & 0 \\
\hline 9 & 0.388 & -0.012 & -0.054 & 0.033 & -0.134 & -0.018 & $\ldots$ & 0.002 & 0.001 & 0.026 & 0 & 1 \\
\hline 10 & 0.387 & -0.017 & -0.064 & 0.031 & -0.119 & -0.022 & $\ldots$ & 0.004 & 0.006 & 0.030 & 1 & 0 \\
\hline 11 & 0.391 & -0.017 & -0.062 & 0.030 & -0.133 & -0.015 & $\ldots$ & -0.008 & -0.004 & 0.033 & 1 & 0 \\
\hline 12 & 0.392 & -0.017 & -0.062 & 0.035 & -0.124 & -0.024 & $\ldots$ & -0.001 & 0.001 & 0.033 & 1 & 0 \\
\hline 13 & 0.394 & -0.006 & -0.065 & 0.041 & -0.133 & -0.014 & $\ldots$ & 0.003 & 0.004 & 0.029 & 1 & 0 \\
\hline 14 & 0.396 & -0.010 & -0.058 & 0.042 & -0.137 & -0.019 & $\ldots$ & 0.011 & 0.016 & 0.027 & 1 & 0 \\
\hline 15 & 0.400 & -0.015 & -0.061 & 0.040 & -0.150 & -0.011 & $\ldots$ & -0.002 & 0.003 & 0.038 & 1 & 0 \\
\hline 16 & 0.398 & -0.021 & -0.055 & 0.037 & -0.148 & -0.012 & $\ldots$ & 0.011 & -0.007 & 0.025 & 1 & 0 \\
\hline 17 & 0.401 & -0.017 & -0.065 & 0.039 & -0.154 & -0.010 & $\ldots$ & 0.010 & 0.003 & 0.025 & 1 & 0 \\
\hline 18 & 0.401 & -0.021 & -0.069 & 0.038 & -0.152 & -0.013 & $\ldots$ & -0.009 & 0.002 & 0.038 & 1 & 0 \\
\hline 19 & 0.384 & -0.012 & -0.047 & 0.029 & -0.107 & -0.008 & $\ldots$ & -0.001 & 0.003 & 0.027 & 1 & 0 \\
\hline 20 & 0.391 & -0.014 & -0.053 & 0.037 & -0.129 & -0.013 & $\ldots$ & -0.003 & -0.002 & 0.037 & 1 & 0 \\
\hline 21 & 0.716 & 0.014 & -0.080 & 0.097 & -0.195 & -0.099 & $\ldots$ & -0.025 & 0.013 & 0.089 & 1 & 0 \\
\hline 22 & 0.599 & -0.035 & -0.095 & 0.039 & -0.220 & -0.012 & $\ldots$ & 0.010 & 0.048 & 0.044 & 1 & 0 \\
\hline 23 & 0.705 & -0.024 & -0.087 & 0.039 & -0.167 & -0.028 & $\ldots$ & 0.044 & -0.040 & 0.028 & 1 & 0 \\
\hline 24 & 0.803 & -0.053 & -0.093 & 0.048 & -0.158 & -0.019 & $\ldots$ & 0.008 & -0.013 & 0.008 & 1 & 0 \\
\hline 25 & 0.784 & -0.022 & -0.076 & 0.055 & -0.180 & -0.034 & $\ldots$ & -0.008 & -0.021 & -0.072 & 1 & 0 \\
\hline 26 & 0.952 & -0.031 & -0.074 & 0.039 & -0.083 & 0.044 & $\ldots$ & 0.002 & -0.017 & -0.006 & 1 & 0 \\
\hline 27 & 0.863 & -0.029 & -0.079 & 0.057 & -0.145 & 0.007 & $\ldots$ & -0.003 & 0.019 & 0.060 & 1 & 0 \\
\hline 28 & 0.890 & -0.023 & -0.079 & 0.037 & -0.108 & -0.019 & $\ldots$ & 0.001 & 0.003 & 0.032 & 1 & 0 \\
\hline 29 & 0.782 & -0.027 & -0.081 & 0.037 & -0.134 & -0.012 & $\ldots$ & 0.000 & -0.012 & 0.038 & 1 & 0 \\
\hline 30 & 0.886 & -0.003 & -0.068 & 0.038 & -0.104 & 0.011 & $\ldots$ & 0.042 & -0.015 & 0.009 & 1 & 0 \\
\hline 31 & 1.000 & -0.015 & -0.068 & 0.041 & -0.077 & -0.006 & $\ldots$ & 0.011 & -0.006 & 0.011 & 1 & 0 \\
\hline 32 & 0.854 & -0.020 & -0.061 & 0.040 & -0.120 & -0.016 & $\ldots$ & 0.022 & 0.011 & 0.013 & 1 & 0 \\
\hline 33 & 0.875 & -0.014 & -0.067 & 0.043 & -0.119 & -0.005 & $\ldots$ & 0.002 & 0.005 & 0.021 & 1 & 0 \\
\hline 34 & 0.785 & -0.031 & -0.059 & 0.033 & -0.137 & -0.007 & $\ldots$ & 0.018 & -0.014 & 0.024 & 1 & 0 \\
\hline 35 & 0.775 & -0.022 & -0.068 & 0.038 & -0.152 & -0.010 & $\ldots$ & 0.013 & -0.026 & 0.016 & 1 & 0 \\
\hline 36 & 0.846 & -0.031 & -0.075 & 0.036 & -0.117 & -0.007 & $\ldots$ & -0.008 & -0.043 & 0.015 & 1 & 0 \\
\hline
\end{tabular}




\section{Autoreclosure Flow Chart on TL}

Figure 13 shows the flow chart to classify the permanent or temporary fault on the TL. In this context, the discrete voltage values were registered by the protection relay at one end of the TL. Then, the PCs were calculated. Accordingly, if the $I_{\text {vark }}$ value did not exceed the $t_{h v}$ value, the eigenvalues' magnitude was continuously updated and analyzed by the protection relay algorithm. However, if the $I_{\text {vark }}$ value was higher than the $t_{h v}$ set, the number of eigenvalues and eigenvector were determined and chosen. The PC numbers chosen were assigned as inputs to the classifier based on SVM, where the permanent and temporary faults can be identified.

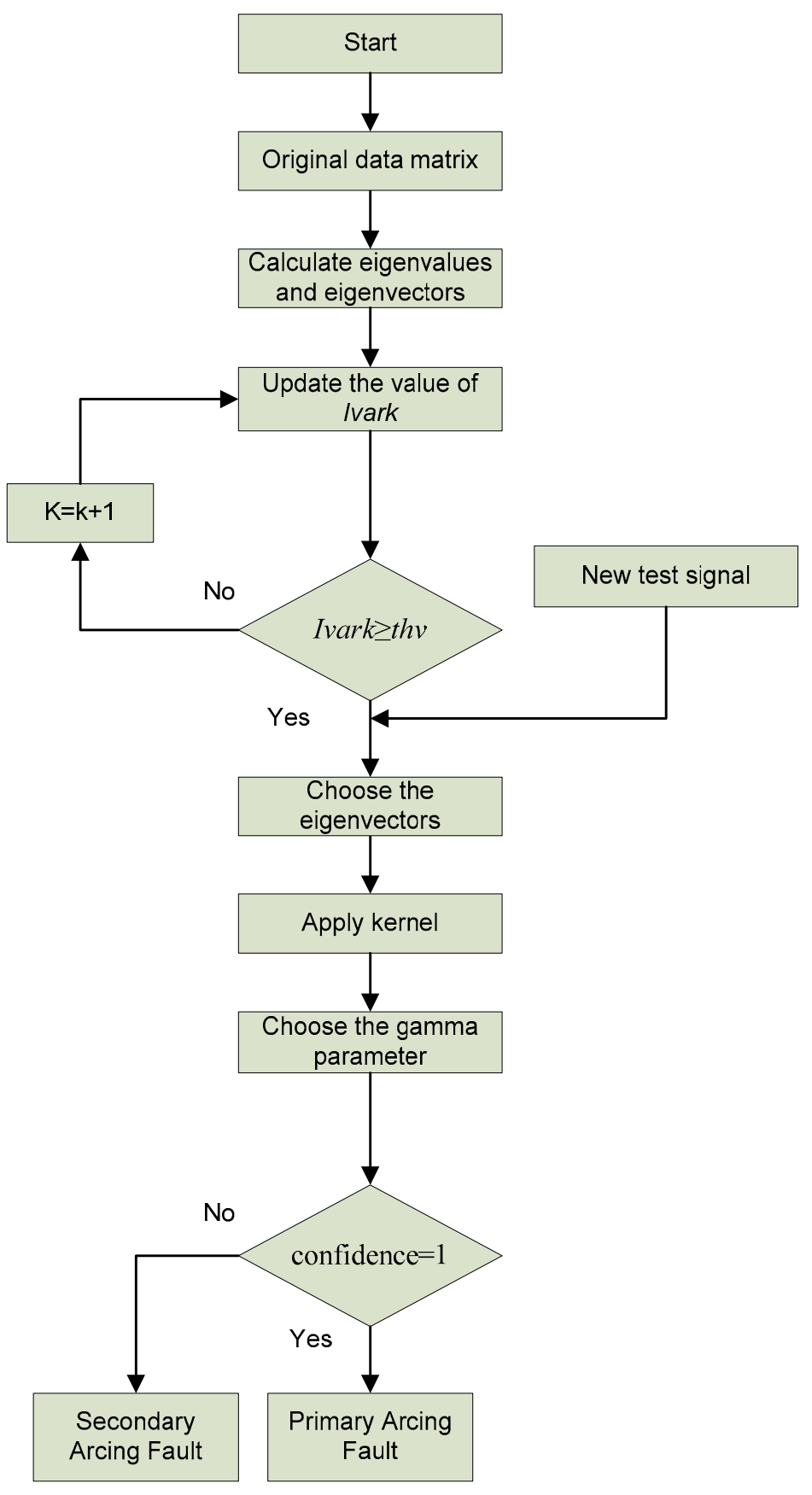

Figure 13. Flow chart of the proposed method. 


\section{Conclusions}

In this proposed research, the main goal was to develop a novel algorithm for single-phase reclosing on TLs, which must be able to classify the fault type (permanent or temporary). The discrete voltage samples from one end of the TL and the PC patterns, as input in the classifier based on SVM, were used for identification of permanent and temporary faults.

Besides that, in this work, a comprehensive bibliographic review of various techniques, methodologies and algorithms useful to single-pole autoreclosure on TLs is presented. Unlike previous algorithms, the proposed algorithm did not need to extract harmonic components using any mathematical tools.

In the results section, it was shown that the proposed algorithm had a successful behavior for all 140 cases the study simulated. Thus, it was able to differentiate or recognize the fault type depending on the eigenvectors and eigenvalues, which allowed TL protection relay to initiate single-phase tripping.

Besides that, as a comparison of the performance of the proposed algorithm based on PCA in order to analyze permanent or temporary fault signal, these signals were also processed by using the MRA. However, the PCA had a better performance than MRA to differentiate those fault spectrums.

In order to analyze on-line new test fault signals, the proposed algorithm used only the eigenvectors chosen, which reduced the processing time. Therefore, it can be used as an option to the traditional reclosing relay algorithms.

Author Contributions: J.M. and E.M. performed the experimental activity and the data processing; J.M. and E.O. contributed to the conceptualization and the definition of the methodology proposed; J.M. and E.M., carried out the data acquisition in the simulation; G.I.-O. prepared the simulation model of primary and secondary arc. J.M., and E.M. prepared the first draft of the manuscript; J.M., E.O. and G.I.-O. reviewed and edited the manuscript. All the authors approved the submitted version of this manuscript.

Funding: This project received funding from the Grupo de Investigación de Energías GIE at the Universidad Politécnica Salesiana.

Conflicts of Interest: The authors declare no conflict of interest.

\section{Nomenclature}

$\begin{array}{ll}\text { IEEE } & \text { Institute of Electrical and Electronics Engineers } \\ \text { EPS } & \text { Electric power system } \\ \text { MA } & \text { Multivariable analysis } \\ \text { DT } & \text { Dead time } \\ \text { THD } & \text { Total harmonic distortion } \\ \text { EHV } & \text { Extra high voltage } \\ \text { ATP } & \text { Alternative transients program } \\ \text { TL } & \text { Transmission Line } \\ \text { SVM } & \text { Support vector machine } \\ \text { WT } & \text { Wavelet transform } \\ \text { DWT } & \text { Discrete wavelet transform } \\ \text { SPAR } & \text { Single-pole automatic reclosure } \\ \text { SPT } & \text { Signal Processing Techniques } \\ \text { DFT } & \text { Discrete Fourier transform } \\ \text { HDI } & \text { Harmonic distortion index } \\ \text { KBT } & \text { Karen-bell transform } \\ \text { SE } & \text { Spectral energy } \\ \text { FL } & \text { Fuzzy logic } \\ \text { FT } & \text { Fourier transform } \\ \text { ANN } & \text { Artificial neural network } \\ \text { GT } & \text { Gabor transform } \\ \text { EMD } & \text { Empirical mode decomposition }\end{array}$




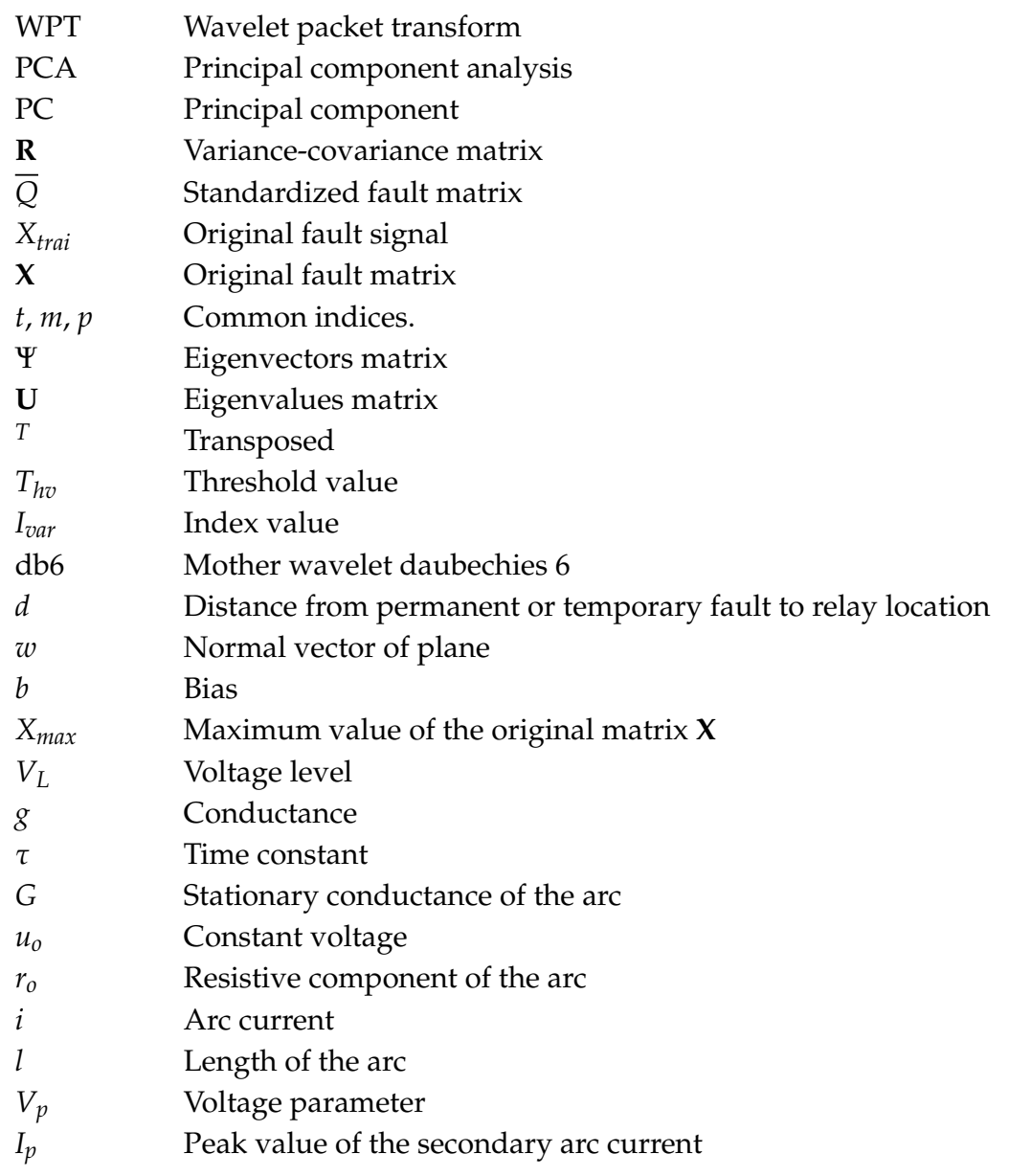

\section{References}

1. Glover, J.D.; Sarma, M.S.; Overbye, T. Power Systems Analysis and Design, 4th ed.; Thomson-Engineering: Cinderford, UK, 2007.

2. IEEE Power System Relaying Committee Working Group. Single-phase tripping and auto re-closing of transmission lines. IEEE Trans. Power Deliv. 1992, 7, 182-192. [CrossRef]

3. Esztergalyos, J.; Andrichak, J.; Colwel1, D.H.; Dawson, D.C.; Jodice, J.A.; Mustaphi, T.J.M.K.K.; Nai, G.R.; Politis, A.; Pope, J.W.; Rockefeller, G.D.; et al. Single phase tripping and auto reclosing of transmission lines; IEEE Committee report. IEEE Trans. Power Deliv. 1992, 7, 182-192.

4. Kizilcay, M.; Priok, T. Digital simulation of fault arcs in power systems. Eur. Trans. Electr. Power 1991, 1, 55-60. [CrossRef]

5. Thomas, D.W.P.; Pereira, E.T.; Christopoulos, C.; Howe, A.F. The simulation of circuit breaker switching using a composite Cassie-modified Mayr model. IEEE Trans. Power Deliv. 1995, 10, 1829-1835. [CrossRef]

6. Dudurych, I.M.; Gallagher, T.J.; Rosolowski, E. Arc Effect on Single-Phase Reclosing time of a UHV power transmission line. IEEE Trans. Power Deliv. 2004, 19, 854-860. [CrossRef]

7. Schavemaker, P.H.; Van der Slui, L. An Improved Mayr-Type arc model based on current-zero measurements. IEEE Trans. Power Deliv. 2000, 15, 580-584. [CrossRef]

8. Bo, Z.Q.; Aggarwal, R.K.; Johns, A.T.; Zhang, B.H.; Ge, Y.Z. New concept in transmission line reclosure using highfrequency fault transients. IEE Proc. Gener. Transm. Distrib. 1997, 144, 351-356. [CrossRef]

9. Russel, B.D.; Council, M.E. Power System Control and Protection; Academic Press: New York, NY, USA, 1978.

10. Jena, P.; Pradhan, A.K. Directional relaying during power swing and single-pole tripping. In Proceedings of the International Conference on Power Systems, Kharagpur, India, 1-6 December 2009.

11. Adly, A.R.; El Sehiemy, R.A.; Abdelaziz, A.Y. A negative sequence superimposedpilot protection technique during single pole tripping. Electr. Power Syst. Res. 2016, 137, 175-189. [CrossRef] 
12. IEEE Power Systems Relaying Committee. Automatic reclosing of transmission lines. IEEE Trans. Power Appar. Syst. 1984, PAS-103, 234-245. [CrossRef]

13. Ali, M.H.; Murata, T.; Tamura, J. Transient stability enhancement by fuzzy logic controlled SMES considering coordination with optimal reclosing of circuit breakers. IEEE Trans. Power Deliv. 2008, 23, 631-640. [CrossRef]

14. Portela, C.M.; Santiago, N.H.C.; Oliveira, O.B.; Dupont, C.J. Modeling of arc extinction in air insulation. IEEE Trans. Electr. Insul. 1992, 27, 457-463. [CrossRef]

15. Eissa, M.M.; Malik, O.P. Experimental results of a supplementary technique for auto-reclosing EHV/UHV transmission lines. IEEE Trans. Power Deliv. 2002, 17, 702-707. [CrossRef]

16. IEEE Power and Energy Society. IEEE Guide for Automatic Reclosing of Circuit Breakers for AC Distribution and Transmission Lines; IEEE Std C37.104-2012; IEEE Power Engineerng Society: Piscataway, NJ, USA, 6 July 2012.

17. Tsuboi, T.; Takami, J.; Okabe, S.; Aoki, K.; Yamagata, Y. Study on a field data of secondary arc extinction time for large-sized transmission lines. IEEE Trans. Dielectr. Electr. Insul. 2013, 20, 2277-2286. [CrossRef]

18. Nagpal, M.; Manuel, S.H.; Bell, B.; Barone, R.; Henville, C.; Ghangass, D. Field verification of secondary arc extinction logic. IEEE Trans. Power Deliv. 2015, 31, 1864-1872. [CrossRef]

19. Choudhury, P. Alberta Interconnected Electric System Protection Standard; Revision 0; AESO Engineering Standard: Calgary, AB, Canada, 1 December 2004.

20. Khodabakhchian, B. EHV Single-pole switching: It is not only a matter of secondary arc extinction. In Proceedings of the International Power System Transient Conf., IPST2013, Vancouver, BC, Canada, 18-20 July 2013.

21. Kappenman, J.G.; Sweezy, G.A.; Koschik, V.; Mustaphi, K.K. Staged fault tests with single phase reclosing on the Winnipeg-Twin cities 500kV interconnection. IEEE Trans. Power Appar. Syst. 1982, PAS-101, 662-673. [CrossRef]

22. Williston, D.; Finney, D. Consequences of out-of-phase reclosing on feeders with distributed generators. In Proceedings of the 66th Annual Georgia Tech Protective Relaying Conference, Atlanta, GA, USA, 25-27 April 2012.

23. Taylor, C.W.; Mittlestadt, W.A.; Lee, T.N.; Hardy, J.E.; Glavitsch, H.; Stranne, G.; Hurley, J.D. Single-pole switching for stability and reliability. IEEE Trans. Power Syst. 1986, 1, 25-36. [CrossRef]

24. Adly, A.R.; El-Sehiemy, R.A.; Abdelaziz, A.Y.; Kotb, S.A. An Accurate Technique for Discrimination between Transient and Permanent Faults in Transmission Networks. Electr. Power Compon. Syst. 2017. [CrossRef]

25. Ghaffarzadeh, N. A new method for recognition of arcing faults in transmission lines using wavelet transform and correlation coefficient. Indones. J. Electr. Eng. Inform. 2013, 1, 1-7. [CrossRef]

26. Fenghua, G.; Shibin, G.; Shuping, L.; Nana, C. A novel technique to distinguish between transient and permanent faults based on signal wavelet singularity detection. In Proceedings of the International Conference on Energy and Environment Technology, Guilin, China, 16-18 October 2009; pp. 35-39.

27. Jamali, S.; Ghaffarzadeh, N. Adaptive single pole autoreclosing using discrete wavelet transform. Eur. Trans. Electr. Power 2011, 21, 973-986. [CrossRef]

28. Yu, I.K.; Song, Y.H. Development of novel adaptive single-pole autoreclosure schemes for extra high voltage transmission systems using wavelet transform analysis. Electr. Power Syst. Res. 1998, 47, 11-19. [CrossRef]

29. Pasand, M.S.; Kadivar, A. Design of an online adaptive auto-reclose algorithm for HV transmission lines. In Proceedings of the International Conference on Power India, New Delhi, India, 10-12 April 2006.

30. Jamali, S.; Ghaffarzadeh, N.A. Wavelet packet based method for adaptive single-pole auto-reclosing. J. Zhejiang Univ. Sci. (Comput. Electron.) 2010, 11, 1016-1024. [CrossRef]

31. Adly, A.R.; El Sehiemy, R.A.; Abdelaziz, A.Y.; Kotb, S.A. Fast fault identification scheme using Karen Bell transformation in conjunction with discrete wavelet transform in transmission lines. In Proceedings of the International Middle East Power Systems Conference, Mansoura, Egypt, 15-17 December 2015; pp. 1-7.

32. Yu, I.K.; Song, Y.H. Wavelet transform and neural network approach to developing adaptive single-pole autoreclosing schemes for EHV transmission systems. IEEE Power Eng. Rev. 1998, 18, 62-64. [CrossRef]

33. Frimpong, E.A.; Okyere, P.Y.; Anto, E.K. Adaptive single-pole autoreclosure scheme based on wavelet transform and multilayer perceptron. J. Sci. Technol. 2010, 30, 102-110. [CrossRef]

34. Lan, H.; Ai, T.; Li, Y. Single phase adaptive reclosure of transmission lines based on EMD approximate entropy and LSSVM with BCC. In Proceedings of the International Conference on Information Engineering and Computer Science, Wuhan, China, 19-20 December 2009; pp. 1-4. 
35. Morales, J.A.; Orduña, E.A.; Rehtanz, C.; Cabral, R.J.; Bretas, A.S. Comparison Between PCA and WT Filtering Methods for Lightning Stroke Classification on Transmission Lines. In Proceedings of the SIPDA, XII International Symposium on Lightning Protection, Belo Horizonte, Brazil, 7-11 October 2013.

36. Morales, J.A.; Orduña, E.A.; Rehtanz, C.; Cabral, R.J.; Bretas, A.S. Comparison between Principal Component Analysis and WaveletTransform 'Filtering Methods for Lightning Stroke Classification onTransmission Lines. Electr. Power Syst. Res. 2015, 118, 37-46. [CrossRef]

37. Ngamsanroaj, K.; Premrudeepreechacharn, S.; Watson, N.R. 500 kV single phase reclosing evaluation using simplified arc model. Emerg. Technol. Adv. Eng. 2004, 4, 1-12.

38. Ahn, S.; Kim, C.; Aggarwal, R.K.; Johns, A.T. An alternative approach to adaptive single pole auto-reclosing in high voltage transmission system based on variable dead time control. IEEE Trans. Power Deliv. 2001, 16, 676-686. [CrossRef]

39. Zhalefar, F.; Zadeh, M.D.; Sidhu, T.A. High-speed adaptive single-phase reclosing technique based on local voltage phasors. IEEE Trans. Power Deliv. 2015, 32, 1203-1211. [CrossRef]

40. Naimi, H.M.; Hasanzadeh, S.; Pasand, M.S. Discrimination of arcing faults on overhead transmission lines for single pole auto-reclosure. Eur. Trans. Electr. Power 2013, 23, 1523-1535.

41. Radojevi, Z.M. Numerical algorithm for adaptive single pole autoreclosure based on determining the secondary arc extinction time. Electr. Power Compon. Syst. 2006, 34, 739-745. [CrossRef]

42. Jamali, S.; Parham, A. New approach to adaptive single pole auto-reclosing of power transmission lines. IET Gener. Transm. Distrib. 2010, 4, 115-122. [CrossRef]

43. Radojevi, Z.; Shin, J. New digital algorithm for adaptive re-closing based on the calculation of the faulted phase voltage total harmonic distortion factor. IEEE Trans. Power Deliv. 2007, 22, 37-41. [CrossRef]

44. Khodadadi, M.; Noori, M.R.; Shahrtash, S. A non-communication adaptive single-pole autoreclosure scheme based on the ACUSUM algorithm. IEEE Trans. Power Deliv. 2013, 28, 2526-2533. [CrossRef]

45. Luxenburger, R.; Schegner, P. Determination of secondary arc extinction time and characterization of fault conditions of single-phase autoreclosures. In Proceedings of the International Conference on Future Power Systems, Amsterdam, The Netherlands, 18 November 2005; pp. 1-5.

46. Golshan, M.H.; Golbon, N. Detecting secondary arc extinction time by analyzing low frequency components of faulted phase voltage or sound phase current waveforms. Electr. Eng. 2006, 88, 141-148. [CrossRef]

47. Jamali, S.; Parham, A. One terminal digital algorithm for adaptive single pole auto-reclosing based on zero sequence voltage. Iran. Electr. Electron. Eng. 2008, 4, 71-78.

48. Chen, Z.; Zhang, B.H.; Bo, Z.Q.; Redfern, M.A. Adaptive optimal reclosure based on analysis of fault current transients. In Proceedings of the 2003 IEEE Power Engineering Society General Meeting (IEEE Cat. No.03CH37491), Toronto, ON, Canada, 13-17 July 2003; pp. 2118-2121.

49. Lin, X.; Wang, B.; Bo, Z.Q.; Klimek, A. An intelligent adaptive reclosure scheme for high voltage transmission lines. In Proceedings of the 2007 International Conference on Intelligent Systems Applications to Power Systems, Niigata, Japan, 5-8 November 2007; pp. 1-6.

50. Ali, A.J.; Allu, A.A.; Antar, R.K. Fuzzy logic technique based single phase autoreclosing protection system of a double circuit transmission line. In Proceedings of the International Conference on Electrical, Communication, Computer, Power, and Control Engineering, Mosul, Iraq, 17-18 December 2013; pp. 31-36.

51. Zahlay, F.D.; Rama Rao, K.S.; Ibrahim, T.B. A new intelligent autoreclosing scheme using artificial neural network and Taguchi's methodology. IEEE Trans. Ind. Appl. 2010, 47, 306-313. [CrossRef]

52. Zoric, K.J.; Jejina, N.D.; Djuric, M.B. Secondary arc faults detection and determine arc extinction time on overhead lines using neural network. Electr. Mach. Power Syst. 2000, 28, 79-85.

53. Kawady, T.A.; Elkalashy, N.I.; Ibrahim, A.E.; Taalab, A.I. Arcing fault identification using combined Gabor Transform-neural network for transmission line. Int. J. Electr. Power Energy Syst. 2014, 61, 248-258. [CrossRef]

54. Jollife, I. Principal Component Analysis; Springer: Berlin, Germany, 1986.

55. Cassie, A.M. A new theory of rupture and circuit severity. CIGRE Rep. 1939, 102, 2-14.

56. Mayr, O. Beiträge zur theorie des statischen und des dynamischen Liechtbogens. Arch. Elecktrotechnic. 1943, 37, 588-608. [CrossRef]

57. Goldberg, S.; Horton, W.F.; Tziouvaras, D. A computer model of the secondary arc in single phase operation of transmission lines. IEEE Trans. Power Deliv. 1989, 4, 286-295. [CrossRef]

58. Jones, G.R. High Pressure Arcs in Industrial Devices; Cambridge University Press: London, UK, 1988.

59. Jones, G.R.; Fang, M.T.C. The physics of high-power arcs. Rep. Prog. Phys. 1980, 43, 1415-1465. [CrossRef] 
60. CIGRE WG 13.01. Practical application of arc physics in circuit breakers. Survey of calculation methods and application guide. Electra 1988, 118, 63-79.

61. ATP DRAW Version 3.5 for Windows 9x/NT/2000/XP Users' Manual; SINTEF Energy Research-Norwegian Univ. Sci. Technol.: Trondheim, Norway, 1999.

62. Marti, J.R. Accurate modeling of frequency-dependent transmission lines in electromagnetic transient simulations. IEEE Trans. Power Appar. Syst. 1982, PAS-101, 147-157. [CrossRef] 